\title{
Absolute Velocity Estimates from Autonomous Underwater Gliders Equipped with Doppler Current Profilers
}

\author{
ROBERT E. TODD \\ Woods Hole Oceanographic Institution, Woods Hole, Massachusetts \\ DANIEL L. RUDNICK AND JEFFREY T. SHERMAN \\ Scripps Institution of Oceanography, University of California, San Diego, La Jolla, California \\ W. BRECHNER OWENS AND LAwRENCE GEORGE \\ Woods Hole Oceanographic Institution, Woods Hole, Massachusetts
}

(Manuscript received 8 August 2016, in final form 4 November 2016)

\begin{abstract}
Doppler current profilers on autonomous underwater gliders measure water velocity relative to the moving glider over vertical ranges of $O(10) \mathrm{m}$. Measurements obtained with $1-\mathrm{MHz}$ Nortek acoustic Doppler dual current profilers (AD2CPs) on Spray gliders deployed off Southern California, west of the Galápagos Archipelago, and in the Gulf Stream are used to demonstrate methods of estimating absolute horizontal velocities in the upper $1000 \mathrm{~m}$ of the ocean. Relative velocity measurements nearest to a glider are used to infer dive-dependent flight parameters, which are then used to correct estimates of absolute vertically averaged currents to account for the accumulation of biofouling during months-long glider missions. The inverse method for combining Doppler profiler measurements of relative velocity with absolute references to estimate profiles of absolute horizontal velocity is reviewed and expanded to include additional constraints on the velocity solutions. Errors arising from both instrumental bias and decreased abundance of acoustic scatterers at depth are considered. Though demonstrated with measurements from a particular combination of platform and instrument, these techniques should be applicable to other combinations of gliders and Doppler current profilers.
\end{abstract}

\section{Introduction}

Autonomous underwater gliders (Davis et al. 2003; Rudnick et al. 2004) have become important platforms for collecting oceanographic measurements (Rudnick 2016). Gliders move vertically through the water by changing their buoyancy, allowing them to climb or dive at typical vertical speeds of $O(0.1) \mathrm{m} \mathrm{s}^{-1}$. Gliders translate their vertical motion into forward motion with wings and by controlling pitch with movable internal battery packs; the resulting sawtooth paths through the water typically have gliders moving horizontally at $O(0.25) \mathrm{m} \mathrm{s}^{-1}$ relative to the water. Though relatively slow, buoyancy-driven gliders are capable of long-endurance (weeks to months long) missions covering hundreds to thousands of kilometers through the water.

Corresponding author e-mail: Robert E. Todd, rtodd@whoi.edu
Velocity estimates from gliders are obtained three ways. Estimates of absolute currents averaged (spatially and temporally) between surfacings of a glider are obtained by comparing the predicted displacement using a model of glider flight and measurements of pressure, pitch, and heading to actual displacement measured by GPS; the resulting velocity estimates, which we refer to as vertically averaged currents given the near-constant vertical speed of a glider during a dive (Rudnick and Cole 2011), are typically accurate to within $0.01 \mathrm{~m} \mathrm{~s}^{-1}$ (Eriksen et al. 2001; Todd et al. 2011b). Estimates of vertical shear are obtained from either thermal wind calculations using measured temperature and salinity profiles or using small high-frequency acoustic Doppler current profilers (ADCPs; Davis 2010; Todd et al. 2011b). These shear profiles are referenced to vertically averaged current estimates to produce absolute velocity profiles.

The long duration and slow movement of gliders makes them prone to biofouling, which causes changes 

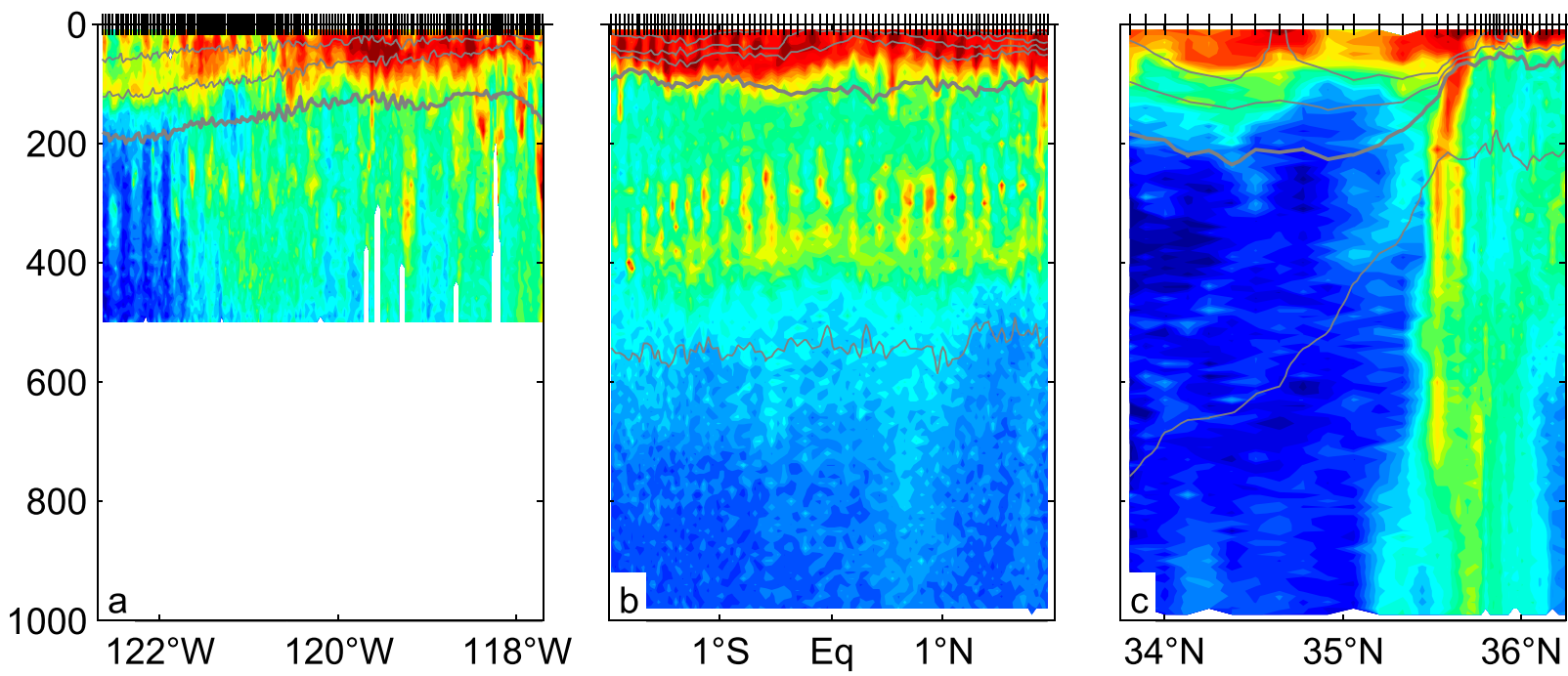

1-MHz Acoustic Backscatter (dB)

FIG. 1. Example transects of 1-MHz acoustic backscatter measured by gliders in three different regions. (a) Along CalCOFI Line 90.0 off Southern California from Spray glider mission 157030, (b) along $93^{\circ} \mathrm{W}$ in the eastern equatorial Pacific from mission 152058 , and (c) along a transect across the Gulf Stream near Cape Hatteras from mission 15A065. Locations of the observations are shown in Fig. 4. Gray contours are isopycnals with a contour interval of $1 \mathrm{~kg} \mathrm{~m}^{-3}$, and the bold line is the $26 \mathrm{~kg} \mathrm{~m}^{-3}$ isopycnal. Tick marks on the upper axes denote the locations of individual profiles.

in flight characteristics throughout a mission (Davis et al. 2012). To avoid biases in vertically averaged current estimates, these changes in flight characteristics, particularly angles of attack and sideslip, must be accounted for when calculating dead-reckoned displacements while a glider is submerged. Davis et al. (2012) and Rudnick et al. (2013) each describe methods of inferring time-dependent flight characteristics using models of glider flight dynamics. Here we demonstrate that measurements of water velocity relative to a glider from an ADCP can be used to estimate angles of attack and sideslip that can be used to correct vertically averaged current estimates.

Using glider-mounted ADCPs to measure vertical shear is advantageous since both components of the horizontal velocity can be measured and velocity profiles can be obtained from individual glider dives. Geostrophic shear estimates, on the other hand, are limited to the cross-track component of the velocity and must be smoothed horizontally and temporally to remove the effects of unbalanced high-frequency motions (e.g., internal waves; Todd et al. 2011b) that are aliased with horizontal variability due to the relatively slow movement of gliders (Rudnick and Cole 2011). However, velocity profiling with ADCPs requires sufficient acoustic scatterers throughout the sampled portion of the water column. The availability of acoustic scatterers typically decreases with depth below the euphotic zone and horizontally away from boundaries (e.g., Fig. 1). If ADCP performance at depth is impaired by a lack of acoustic scatters, velocity solutions are degraded over the full sampling range. Here we expand upon the inverse technique of Todd et al. (2011b, their appendix B) using observations from the eastern equatorial Pacific, where geostrophic calculations are not possible due to the Coriolis parameter vanishing at the equator, as well as observations in eastern and western boundary current systems.

This paper details the complete method we use to produce our best estimates of both absolute vertically averaged currents and absolute horizontal current profiles using glider-mounted ADCPs. Section 2 describes the glider platform and Doppler current profiler that we use, quality control procedures for glider-based Doppler current profiler data, and the glider missions that provide the observations used herein. Section 3 a describes how glider-based Doppler current measurements can be used to infer glider flight characteristics and, in turn, correct vertically averaged current estimates to account for accumulated biofouling or other changes in glider flight during a mission. Section $3 b$ details the inverse method for estimating absolute current profiles, identifies and corrects for instrumental bias, and considers 
the overall accuracy of estimated current profiles. Section 4 summarizes the results.

\section{Instrumentation and deployments}

\section{a. Spray glider}

The observations presented here were collected using Spray gliders (Sherman et al. 2001; Rudnick et al. 2016). Like other autonomous underwater gliders (Davis et al. 2003; Rudnick et al. 2004), Spray is a buoyancy-driven vehicle that uses changes in volume to rise and fall through the water column. By shifting internal battery packs fore and aft, Spray maintains a nose-up (nose-down) pitch during ascent (descent) that allows its wings to translate vertical motion into forward motion. For a vertical speed of approximately $0.1 \mathrm{~m} \mathrm{~s}^{-1}$, Spray moves horizontally at approximately $0.25 \mathrm{~m} \mathrm{~s}^{-1}$ with a pitch of $17^{\circ}$. Spray controls its heading by moving an internal battery pack side to side to induce roll and sideslip; Seaglider (Eriksen et al. 2001) operates similarly, while the Slocum glider (Schofield et al. 2007) uses a rudder for heading control. Measurements of a glider's heading, pitch, and roll are obtained from a Precision Navigation Inc. TCM2 compass in the nose of the glider. These compasses typically exhibit heading- and pitch-dependent errors in reported heading that are measured prior to glider deployment and then are used to create a lookup table for postdeployment compass corrections.

\section{b. Doppler current profiler}

For this analysis, measurements of water velocity relative to the glider were obtained with $1-\mathrm{MHz}$ Nortek acoustic Doppler dual current profilers (AD2CPs). These newer instruments are now replacing the $750-\mathrm{kHz}$ Sontek acoustic Doppler profilers (ADPs) that have been flown on Spray gliders for more than a decade (Davis 2010; Todd et al. 2011b). The AD2CP is a broadband instrument with four transducers mounted in a Janus configuration with two beams oriented $25^{\circ}$ from vertical toward port and starboard (Fig. 2a) and the forward and aft beams oriented $47.5^{\circ}$ from vertical (Fig. 2b); this configuration allows for the central axis of a three-beam configuration to be oriented vertically when the glider is pitched up or down at approximately $17.4^{\circ}$ (Fig. 2c). Individual beams in the resulting threebeam pattern are angled approximately $30.1^{\circ}$ from the central axis and distributed nearly symmetrically about the central axis. The instrument is mounted looking downward in the flooded instrument bay of the glider (Fig. 2c).

For missions on Spray gliders, the AD2CP is configured to collect relative velocity measurements in 15 sampling cells of 2-m vertical extent each (e.g., Fig. 3a).
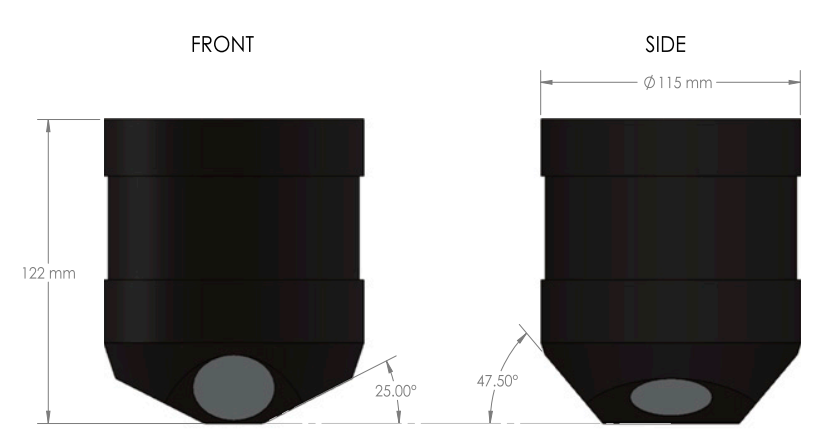

(a)

(b)

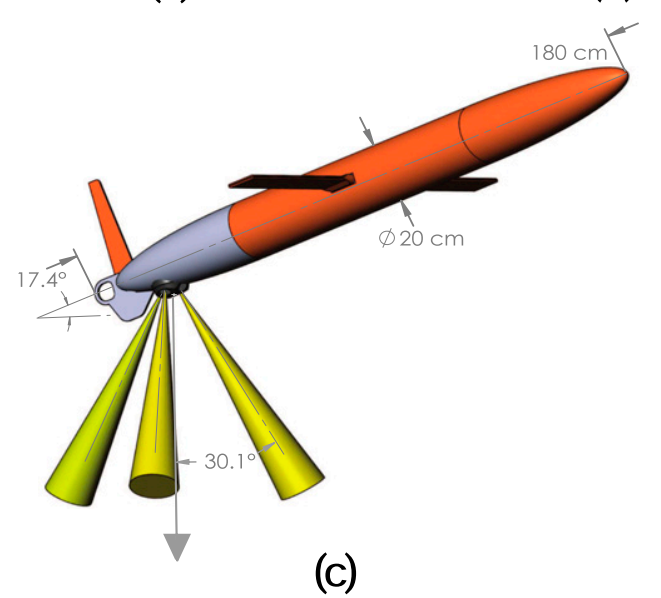

FIG. 2. Schematics of the 1-MHz Nortek AD2CP and its installation in a Spray glider. (a) Front and (b) side views of the instrument showing the size of the instrument and the geometry of the four transducers. (c) The downward-looking three-beam pattern when the glider is pitch upward at $17.4^{\circ}$; the forward-looking beam is not shown, since it is not used for velocity measurements during ascent.

The blanking distance is set to $0.1 \mathrm{~m}$ so that the first sampling cell is centered $1.1 \mathrm{~m}$ below the glider. Eight samples are taken within a 1-s period every 30 s during the ascending portion of each glider dive. Raw data are logged internally by the $\mathrm{AD} 2 \mathrm{CP}$ with no averaging or rotations. The AD2CP separately measures orientation, pressure, and other variables also measured by Spray; we use the glider's measurements throughout our processing. Though data are processed on board the glider to produce a single shear profile over the entire glider dive for transmission to shore, our analysis focuses on the full-resolution $\mathrm{AD} 2 \mathrm{CP}$ data that are downloaded after the glider is recovered. The AD2CP is powered by the glider's internal batteries (52 DD-sized lithium cells with a total energy of $13 \mathrm{MJ}$; Sherman et al. 2001). Power requirements of the AD2CP allow for sampling on every dive during a mission lasting at least 110 days. During descent, the $\mathrm{AD} 2 \mathrm{CP}$ may be used as an altimeter; strong returns are used to identify the bottom and to allow the glider to begin ascent before hitting the bottom. Prior to each 

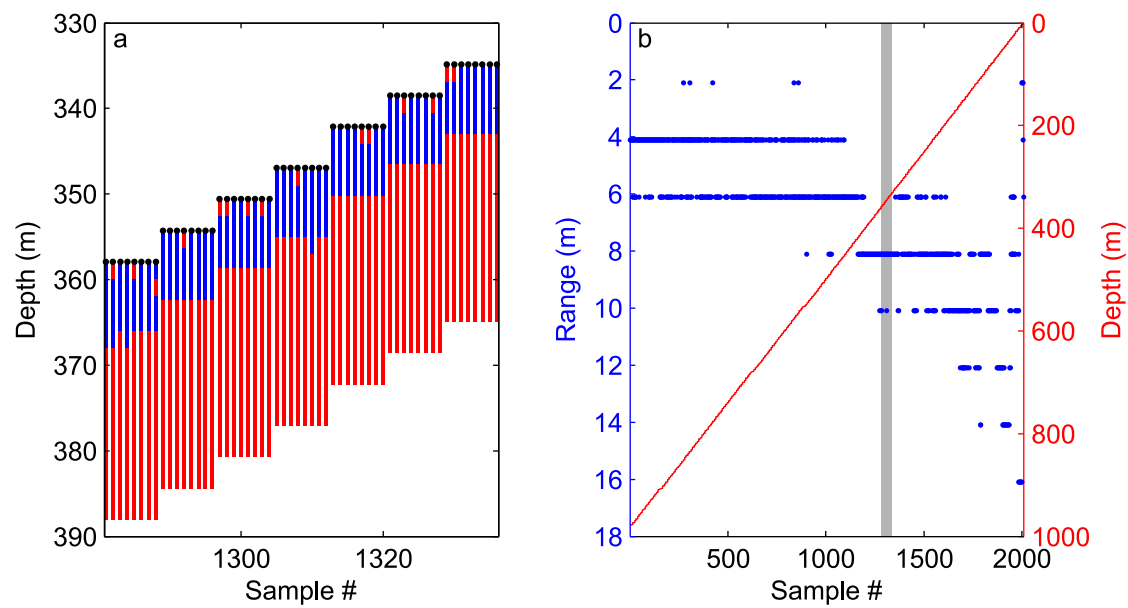

FIG. 3. Example AD2CP sampling and quality control from dive 94 of mission 152058. (a) Sampling pattern as a function of depth and sample number for a portion of the dive [shaded in (b)]; blue and red indicate accepted and rejected samples, respectively, while black dots indicate the depth of the glider during each sample. (b) Effective range of the AD2CP (blue) and glider depth (red) for each sample during the dive. Effective range of the AD2CP increases from approximately $4 \mathrm{~m}$ at $1000 \mathrm{~m}$ to greater than $12 \mathrm{~m}$ near the surface.

glider mission, the transmit and receive functionality of each $\mathrm{AD} 2 \mathrm{CP}$ transducer is verified with a test transducer connected to an oscilloscope.

\section{c. Quality control of Doppler current profiler measurements}

Before further processing, raw data from the $\mathrm{AD} 2 \mathrm{CP}$ are run through a variety of automated quality checks to screen out low-quality measurements. Along-beam velocities in all measurement cells are corrected for the local sound speed following Fischer and Visbeck (1993) by multiplying each along-beam velocity profile by $c(z) / c_{0}$, where $c(z)$ is the local sound speed based on the glider's CTD measurements and $c_{0}=1500 \mathrm{~m} \mathrm{~s}^{-1}$ is the fixed sound speed used by the AD2CP. Measurement cells that fall below the detected bottom are excluded. Cells that report velocities relative to the glider exceeding $0.5 \mathrm{~m} \mathrm{~s}^{-1}$ are excluded under the assumption that realistic ocean currents in areas sampled by gliders do not change by such a large amount over the 30-m vertical sampling range of the $\mathrm{AD} 2 \mathrm{CP}$. When the glider's attitude differs from the nominal $17.4^{\circ}$ pitch and zero roll, measurement cells from different beams become separated vertically due to the spreading of the three-beam pattern away from the glider; when pitch and/or roll cause corresponding cells at a particular range on separate beams to be separated vertically by more than the length of one velocity estimation bin (chosen to be $10 \mathrm{~m}$, see below), measurements from those cells are discarded. Measurements with reported correlation values less than 0.5 are excluded. At high return amplitudes, $\mathrm{AD} 2 \mathrm{CP}$ data quality is degraded, so data with return amplitudes exceeding $75 \mathrm{~dB}$ are discarded; these data are exclusively near the surface and in the measurement cells nearest to the instrument. Laboratory measurements and examination of return amplitude at depth indicate a noise floor of $25 \mathrm{~dB}$ for the AD2CP. We define the signal-to-noise ratio (SNR) as SNR $=10^{\left(S_{\mathrm{dB}}-N_{\mathrm{dB}}\right) / 10}$, where $S_{\mathrm{dB}}$ and $N_{\mathrm{dB}}$ are the signal strength and noise, respectively, in decibels. AD2CP measurements with SNRs less than 20 (or a signal about $13 \mathrm{~dB}$ above noise) are also discarded. Following these checks, the standard deviation of along-beam velocities across eight-ping ensembles is checked; measurements from ensembles with standard deviations exceeding $0.1 \mathrm{~m} \mathrm{~s}^{-1}$ are discarded, assuming that water velocities should not change significantly during the time required to collect an ensemble (approximately $1 \mathrm{~s}$ ). Finally, measurements from pings in which the standard deviation of the vertical velocity across range cells exceeds $0.1 \mathrm{~m} \mathrm{~s}^{-1}$ are excluded. Figure 3 shows the accepted and excluded samples during a portion of a typical profile and the corresponding effective range (i.e., most distant sampling cell passing quality control) from $1000 \mathrm{~m}$ to the surface; the effective range of the AD2CP typically decreases with increasing depth due to a reduction in backscatter intensity.

\section{d. Glider missions}

Deployments of AD2CPs on Spray gliders began in early 2013 with short-duration tests off of the coast of 


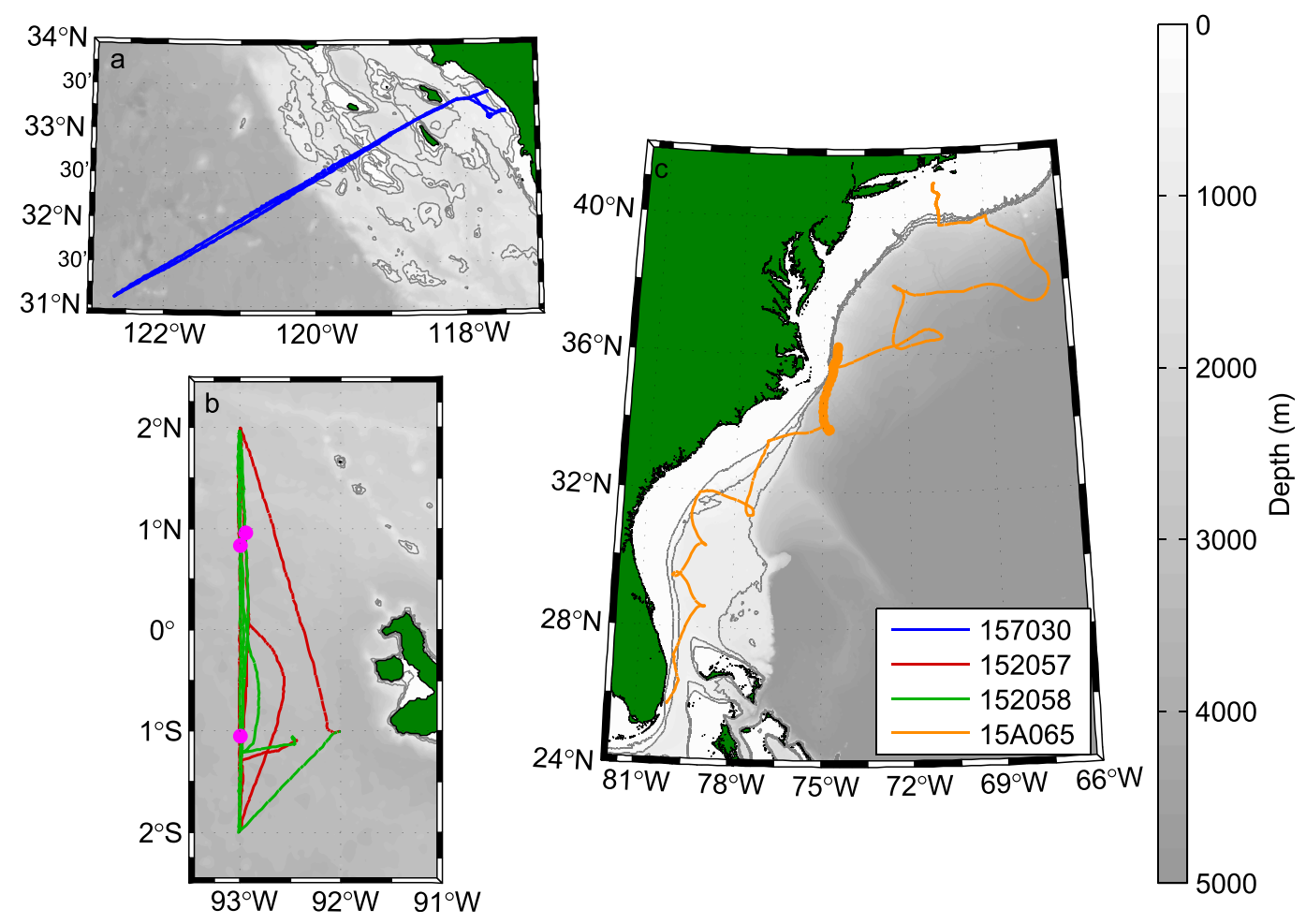

FIG. 4. Maps showing glider trajectories for the four glider missions used in this analysis. (a) Trajectory for mission 157030 along CalCOFI Line 90.0 off Southern California (blue). (b) Trajectories for missions 152057 (red) and 152058 (green) west of the Galápagos. Magenta circles in (b) denote the locations at which the two gliders crossed paths. (c) Trajectory for mission 15A065 in and near the Gulf Stream along the U.S. East Coast (orange) with the location of the transect in Fig. 13 shown with the bold line.

San Diego, California. Operational deployments of the $\mathrm{AD} 2 \mathrm{CP}$ began along established glider lines off the California coast in September 2013 with additional missions west of the Galápagos Islands from April 2014, near Palau from September 2014, and in the Gulf Stream from July 2015. This analysis focuses on four glider missions, which are named using a shorthand of the form YYMSSS, where YY is the last two digits of the year, $M$ is the hexadecimal month, and SSS is the serial number of the glider.

Mission 157030 took place along California Cooperative Oceanic Fisheries Investigations (CalCOFI) Line 90.0 off Southern California (Fig. 4a) from 14 July to 30 October 2015 as part of the ongoing California Underwater Glider Network (Davis et al. 2008; Todd et al. 2011b,a, 2012; Ohman et al. 2013; Johnston and Rudnick 2015; Zaba and Rudnick 2016; Rudnick et al. 2016). The glider completed four cross-shore transects from the coast to approximately $525 \mathrm{~km}$ offshore, sampling from the surface to $500 \mathrm{~m}$ approximately every $3 \mathrm{~h}$. The glider had little growth on it upon recovery.

Missions 152057 and 152058 took place in the eastern equatorial Pacific to the west of the Galápagos Islands
(Fig. 4b) as part of a program to study the Equatorial Undercurrent and equatorial front. Both gliders were deployed from 6 February 2015 to 14 May 2015, spending most of their missions surveying along $93^{\circ} \mathrm{W}$. Each glider completed four crossings of the Equatorial Undercurrent and equatorial front, profiling to $1000 \mathrm{~m}$ approximately every $6 \mathrm{~h}$. As has been the case for each glider we have deployed near the Galápagos, these two gliders experienced biofouling, primarily by barnacles (e.g., Fig. 5). Drag induced by the biofouling progressively slowed the gliders and led to changes in the gliders' angles of attack.

Mission 15A065 was part of a pilot program demonstrating the usefulness of gliders for collecting subsurface measurements within the Gulf Stream along the U.S. East Coast. The mission began a few miles offshore of Miami, Florida, on 1 October 2015. The glider was piloted back and forth across the Gulf Stream as it was advected downstream (Fig. 4c) and then flown onto the continental shelf south of New England for recovery on 7 January 2016. The glider sampled to the shallower of $1000 \mathrm{~m}$ or a few meters above the bottom with profile spacing a function of 


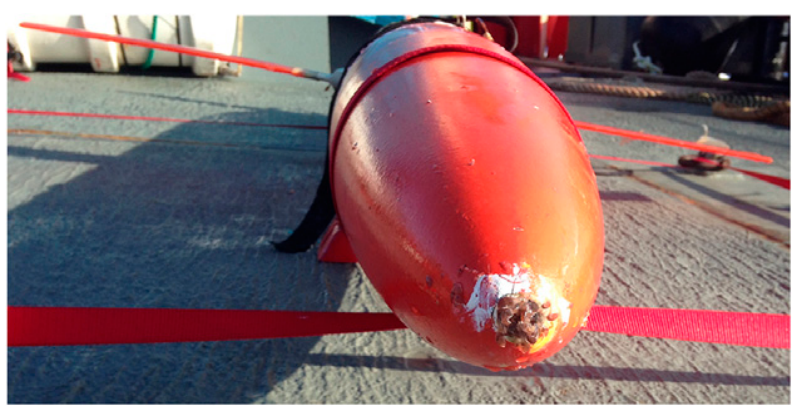

FIG. 5. Barnacles on the nose of Spray 57 at the end of mission 152057 near the Galápagos. In the water, these barnacles extend their feeding appendages, substantially increasing drag on the glider.

profile depth. The glider had minimal biofouling upon recovery.

\section{Results and discussion}

\section{a. Correcting vertically averaged currents}

Here we use AD2CP measurements to infer timedependent glider flight characteristics and use those to correct vertically averaged current estimates. We first demonstrate the method using data from the minimally biofouled mission 157030 off Southern California. We then apply the same methodology to mission 152058 from the eastern equatorial Pacific, which had worse biofouling.

\section{1) NeARest-Cell Velocities}

We begin by establishing that $\mathrm{AD} 2 \mathrm{CP}$ measurements of water velocity relative to the glider from the measurement cells nearest to the glider are dominated by the glider's speed through the water. The first $2-\mathrm{m}$ measurement cell is centered $1.1 \mathrm{~m}$ from the glider, so it is reasonable to expect that there is little current shear over that range and that the measurement is taken outside of the glider's boundary layer. We compare these nearest-cell measurements from the $\mathrm{AD} 2 \mathrm{CP}$ to the glider's motion through the water that is expected from the simple model of glider flight that is used to estimate dead-reckoned displacement as part of the vertically averaged current estimate (e.g., Todd et al. 2009, 2011b).

\section{(i) Vertical velocity}

We first consider the glider's vertical velocity, for which we take the independent estimate, $\tilde{w}$, to be the time rate of change of depth inferred from glider measurements of pressure every $8 \mathrm{~s}$ combined with the hydrostatic relationship (Fofonoff and Millard 1983). We compare $\tilde{w}$ to nearest-cell measurements of relative vertical velocity from the $\mathrm{AD} 2 \mathrm{CP}, \hat{w}$, which are constructed by standard rotations of along-beam velocities based on beam geometry and the glider's reported pitch and roll. In terms of measured velocities $\left(v_{1}, v_{2}, v_{3}\right)$ in the frame of the $\mathrm{AD} 2 \mathrm{CP}$, the relative vertical velocity from the $\mathrm{AD} 2 \mathrm{CP}$ is

$$
\hat{w}=v_{1} \sin \hat{\phi}+v_{2} \cos \hat{\phi} \sin \hat{\theta}+v_{3} \cos \hat{\phi} \cos \hat{\theta},
$$

where $\hat{\phi}$ and $\hat{\theta}$ are the pitch and roll, respectively, reported by the glider. Close examination reveals that the AD2CP-based estimates of the glider's ascent speed are typically biased; for mission $157030, \hat{w}$ is approximately $0.003 \mathrm{~m} \mathrm{~s}^{-1}$ faster than $\tilde{w}$ during ascent (Fig. 6a). The observed bias is consistent with a portion of the glider's horizontal speed being projected into the AD2CP-based
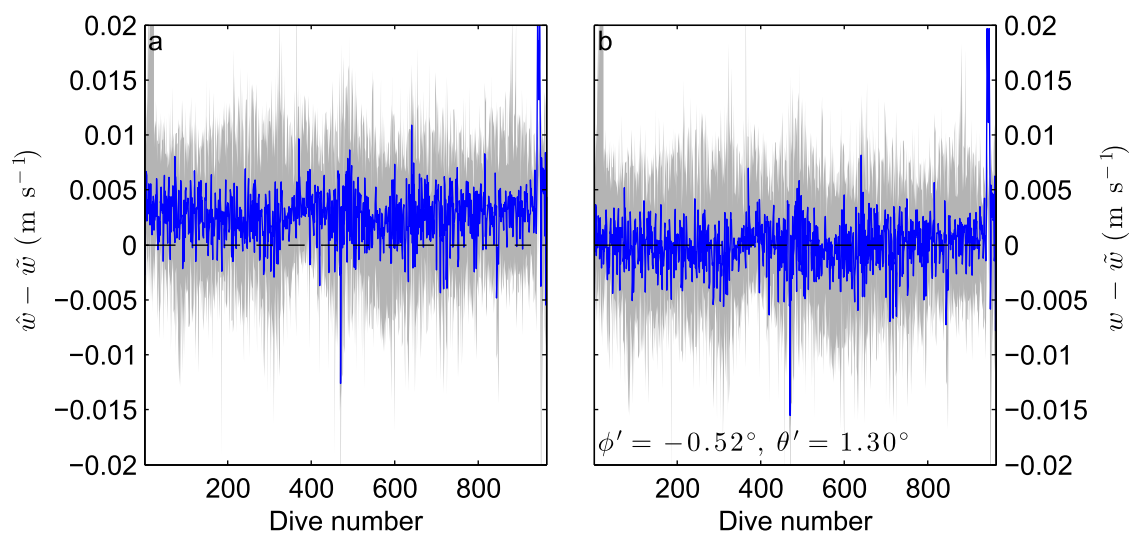

FIG. 6. Differences between AD2CP-derived $(\hat{w})$ and pressure-derived $(\tilde{w})$ estimates of a glider's vertical speed (a) before and (b) after correcting for misalignment of the AD2CP for mission 157030 off Southern California. Blue lines denote the mean difference for each dive, and gray shading indicates the standard deviation of differences for each dive. The values of $\phi^{\prime}$ and $\theta^{\prime}$ used to align the $\mathrm{AD} 2 \mathrm{CP}$ are shown in (b). 

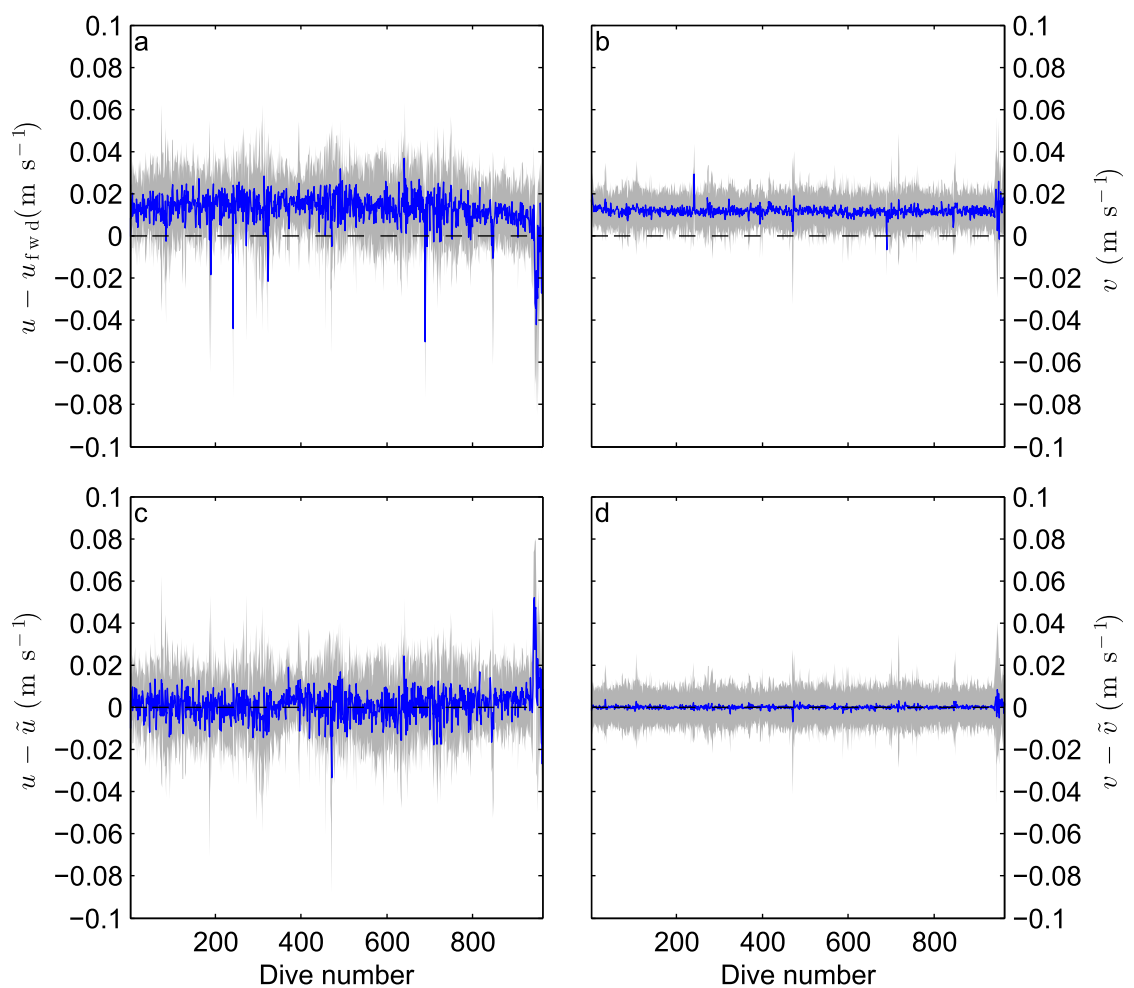

FIG. 7. Differences between AD2CP-derived and flight model-derived estimates of a glider's horizontal velocity for mission 157030 off Southern California. Before corrections, (a) AD2CP-based estimates of $u$ were faster than flight model-derived estimates $\left(u_{\mathrm{fwd}}\right)$, and (b) AD2CP-based estimates of cross-glider velocities $(v)$ were toward the glider's port side. After applying corrections for measured angle of attack and sideslip to model-derived estimates $(\tilde{u}$ and $\tilde{v}),($ c) forward and (d) cross-glider velocity estimates agreed well. Blue lines denote the mean difference for each dive, and gray shading indicates the standard deviation of differences for each dive.

estimate of its vertical speed, which could result from either physical misalignment of the $\mathrm{AD} 2 \mathrm{CP}$ or bias in the glider's reported pitch and roll. These two errors are indistinguishable in their effect on the AD2CP-based estimates of the glider's vertical velocity.

To correct for biases in AD2CP-derived vertical velocity estimates due to projection of horizontal velocity, we write the true pitch $\phi$ and roll $\theta$ of the $\mathrm{AD} 2 \mathrm{CP}$ as $\phi=\hat{\phi}+\phi^{\prime}$ and $\theta=\hat{\theta}+\theta^{\prime}$, where the caret $\left({ }^{(}\right)$ denotes the value reported by Spray and the prime $\left({ }^{\prime}\right)$ denotes a small angle. Substituting these angles into (1) in place of the measured pitch and roll, using small angle identities, and keeping only terms that are linear in the small angles, the relative vertical velocity from the $\mathrm{AD} 2 \mathrm{CP}$ is

$$
\begin{aligned}
w= & \hat{w}+v_{1} \phi^{\prime} \cos \hat{\phi}+v_{2}\left(-\phi^{\prime} \sin \hat{\phi} \sin \hat{\theta}+\theta^{\prime} \cos \hat{\phi} \cos \hat{\theta}\right) \\
& +v_{3}\left(-\phi^{\prime} \sin \hat{\phi} \cos \hat{\theta}-\theta^{\prime} \cos \hat{\phi} \sin \hat{\theta}\right),
\end{aligned}
$$

where $\hat{w}$ is the estimate of vertical velocity using only the glider's reported pitch and roll. We find $\phi^{\prime}$ and $\theta^{\prime}$ by minimizing the mean-square difference between $w$ given by (2) and the $\tilde{w}$ inferred from pressure-based measurements of $d z / d t$; since these are expected to be errors that do not vary during a mission, the minimization is performed over all samples for a given mission.

For mission 157030, the values of $\phi^{\prime}$ and $\theta^{\prime}$ are $-0.52^{\circ}$ and $1.30^{\circ}$, respectively. Applying the correction results in an unbiased estimate of the glider's vertical velocity (Fig. 6b); remaining differences between $w$ and $\tilde{w}$ are attributable to real vertical velocities in the ocean (e.g., due to internal waves).

\section{(ii) Horizontal velocity}

We next compare estimates of the glider's horizontal speed through the water that are derived from the $\mathrm{AD} 2 \mathrm{CP}$ and from glider flight characteristics. AD2CPbased estimates of forward velocity $u$ and sideways velocity $v$ are taken from the nearest-cell measurements with corrections for alignment as discussed above. An initial estimate of the glider's forward speed based on a simple model of glider flight is $u_{\mathrm{fwd}}=\tilde{w} / \tan (\hat{\phi}+\alpha)$, 

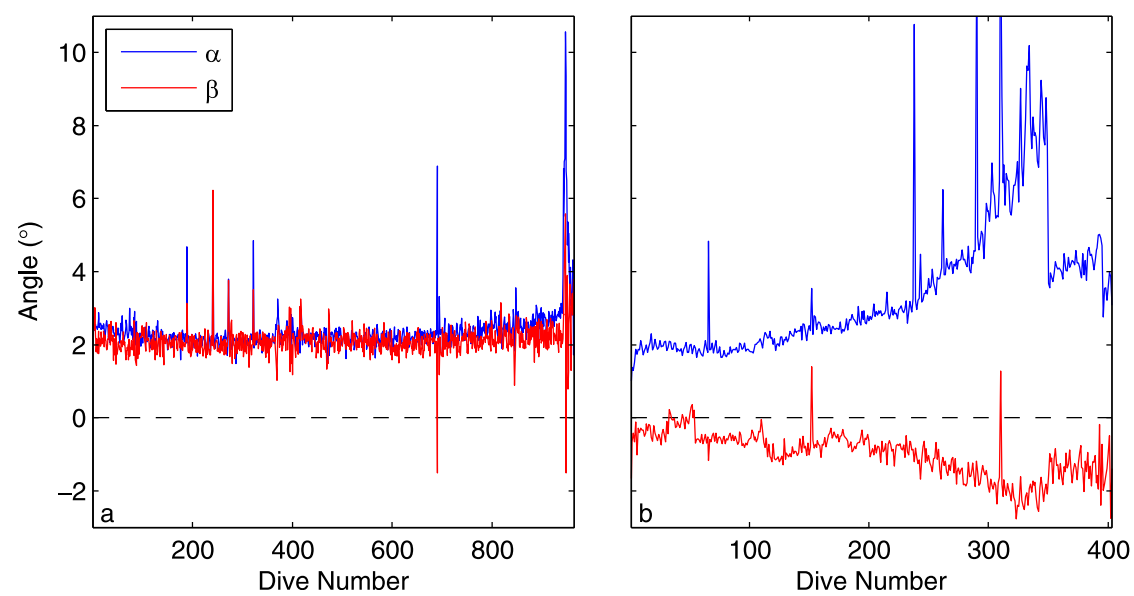

FIG. 8. Inferred angles of attack $\alpha$ (blue) and sideslip $\beta$ (red) for missions (a) 157030 off Southern California and (b) 152058 west of the Galápagos.

where $\hat{\phi}$ is the glider's reported pitch and $\alpha$ is an angle of attack, initially taken to be $3^{\circ}$ (Sherman et al. 2001; Todd et al. 2011b); this initial estimate neglects roll and the resulting induced sideslip.

For mission 157030 off Southern California, Fig. 7a shows that the forward speed measured by the AD2CP is about $0.013 \mathrm{~m} \mathrm{~s}^{-1}$ faster than $u_{\text {fwd }}$ throughout the mission. This nearly constant bias through the mission is consistent with the minimal biofouling found on the glider; a slight slowing in the last third of the mission suggests some minor biofouling. For the same mission, the $\mathrm{AD} 2 \mathrm{CP}$ also measured motion toward the glider's port side at approximately $0.012 \mathrm{~m} \mathrm{~s}^{-1}$ (Fig. 7b); such sideslip is consistent with the measured roll of the glider throughout the mission. It appears that, with corrections for AD2CP alignment, the nearest-cell velocities measured by the $\mathrm{AD} 2 \mathrm{CP}(u, v, w)$ represent a glider's true movement through the water with an accuracy of $0.01 \mathrm{~m} \mathrm{~s}^{-1}$ or better.

\section{2) GLIDER FLIGHT CHARACTERISTICS}

Having established that nearest-cell velocity measurements accurately depict glider motion, we use those measurements to infer the angles of attack $\alpha$ and sideslip $\beta$ for each dive of a mission; dive-dependent values of $\alpha$ and $\beta$ can then be used to correct the estimates of dead-reckoned displacement and vertically averaged currents. The angle of attack is the difference between a glider's glide angle through the water $\gamma=\arctan (w / u)$ and its pitch $\phi$, so an instantaneous estimate of the angle of attack is $\alpha=\arctan (w / u)-\phi$. Similarly, we let the sideslip angle be the angle in the horizontal plane between the glider's forward and cross-glider motion through the water, so an instantaneous estimate of the sideslip angle is $\beta=\arctan (v / u)$. Sherman et al. (2001) and Davis et al. (2012) give more details on Spray flight dynamics. Since these estimates are rather noisy and we expect a glider's flight characteristics to be fairly stable during a dive, we average these estimates over the ascending portion of each glider dive when the AD2CP is sampling. For mission 157030 off Southern California, both the inferred angles of attack and sideslip were approximately $2^{\circ}$ throughout the mission with a slight increase in the angle of attack in the last third of the mission due to the minor biofouling (Fig. 8a). Since the inferred angle of attack for this mission is somewhat smaller than the $3^{\circ}$ angle of attack previously found for Spray gliders (Sherman et al. 2001; Todd et al. 2011b) and the glider was moving forward faster than expected from a basic flight model (Fig. 7a), it is likely that the pitch correction of $\phi^{\prime}=-0.52^{\circ}$ for this mission is largely due to bias in the glider's reported pitch rather than misalignment between the $\mathrm{AD} 2 \mathrm{CP}$ and glider. If so, then our smaller-than-expected angle of attack estimate effectively applies the small angle correction $\phi^{\prime}$ to the glider's reported pitch $\hat{\phi}$ in subsequent calculations. Using dive-dependent angles of attack and sideslip to calculate a glider's dead-reckoned speed through the water $(\tilde{u}, \tilde{v})$ yields substantially improved agreement with first-cell AD2CP measurements (Figs. 7c and 7d).

\section{3) Vertically aVeraged velocities}

We produce updated estimates of vertically averaged currents using the estimates of the glider's deadreckoned displacement through the water that include dive-dependent angles of attack and sideslip. Since mission 157030 experienced minimal biofouling, the changes to vertically averaged current estimates are primarily due to correcting for pitch bias and sideslip, which separately affect the along-glider and cross-glider 

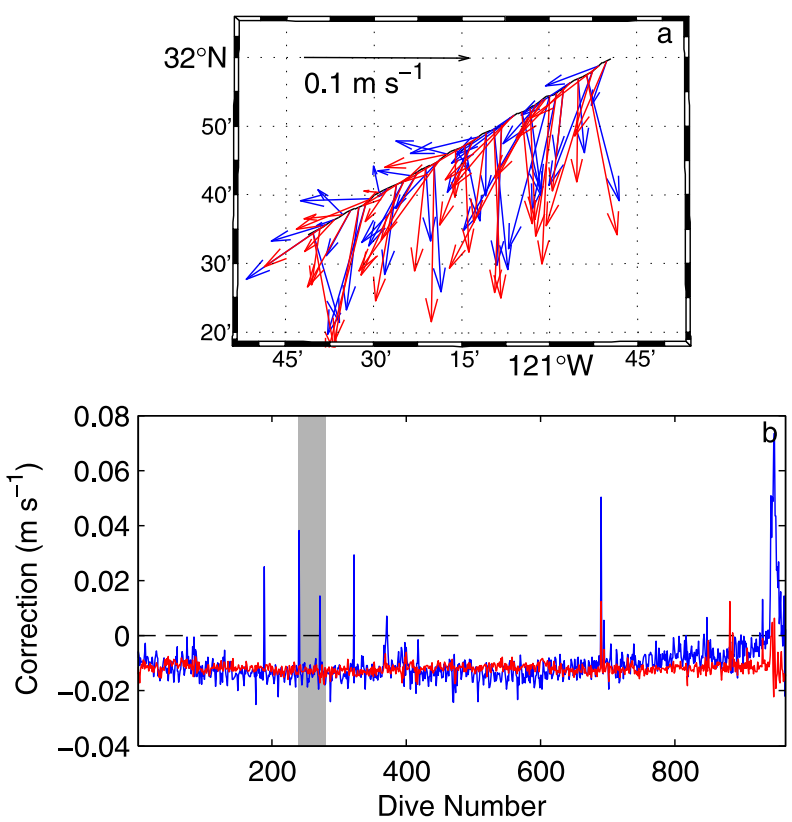

FIG. 9. Corrections to vertically averaged velocity estimates for mission 157030 off Southern California. (a) Vertically averaged current estimates before (blue) and after (red) corrections for angle of attack and sideslip (Fig. 8) for dives 240-280 when the glider was headed northeastward. (b) Changes in magnitude of vertically averaged current parallel (blue) and perpendicular (red) to the glider's mean heading for each dive after corrections; positive changes are forward and toward the glider's port side.

velocity components. For a segment of mission 157030 during which the glider was moving northeastward, Fig. 9a shows vertically averaged current estimates before and after corrections. Corrected current estimates gain a generally southward component due to the combined southwestward (a headwind for the glider) correction from the angle of attack and the southeastward correction for sideslip. Corrections to the along-glider component of the vertically averaged current estimate are typically between -0.015 and $-0.01 \mathrm{~m} \mathrm{~s}^{-1}$ with a trend toward zero in the latter third of the mission; cross-glider corrections are nearly constant at $0.012 \mathrm{~m} \mathrm{~s}^{-1}$ toward the glider's starboard side (Fig. 9b), mirroring the differences between AD2CP-derived estimates of glider speed through water and estimates from the uncorrected flight model (Figs. 7a and 7b).

\section{4) Correcting FOr BIOFOULing}

We now attempt to use AD2CP data to correct vertically averaged current estimates for mission 152058 in the eastern equatorial Pacific, which exhibited heavy biofouling. Alignment corrections of $\phi^{\prime}=-0.35^{\circ}$ and $\theta^{\prime}=0.78^{\circ}$ brought $\mathrm{AD} 2 \mathrm{CP}$-based estimates of vertical velocity into good agreement with pressure-based measurements of $d z / d t$ (not shown). Initial estimates of the glider's forward speed through the water without dive-dependent angles of attack and $\operatorname{sideslip}\left(u_{\text {fwd }}\right)$ were approximately $0.02 \mathrm{~m} \mathrm{~s}^{-1}$ slower than measured by the AD2CP early in the mission, but they became more than $0.06 \mathrm{~m} \mathrm{~s}^{-1}$ faster than measured by the AD2CP later in the mission (Fig. 10a). At dive 350, agreement between $u_{\text {fwd }}$ and $u$ suddenly improved; we attribute this sudden change to the fortuitous removal of accumulated biofouling and note that agreement deteriorated again through the remainder of the mission. The $\mathrm{AD} 2 \mathrm{CP}$ also showed some motion toward the glider's starboard side (Fig. 10b), again consistent with measured roll. Inferred angle of attack $\alpha$ increased from approximately $2^{\circ}$ at the beginning of mission 152058 to greater than $8^{\circ}$ by dive 350 , and then dropped to near $4^{\circ}$ before increasing slowly again as biofouling continued to accumulate (Fig. 8b). Sideslip angle $\beta$ remained near $-1^{\circ}$ through dive 200 , trended toward $-2^{\circ}$ as fouling worsened, and then remained near $-1.5^{\circ}$ after dive 350 (Fig. $8 \mathrm{~b}$ ). Using these dive-dependent values of $\alpha$ and $\beta$ to calculate dead-reckoned displacement through the water leads to very good agreement with $\mathrm{AD} 2 \mathrm{CP}$ measurements of horizontal velocity throughout the mission (Figs. 10c and 10d).

Changes to vertically averaged current estimates for mission 152058 were dominated by changes to the alongglider component of the vertically averaged current (e.g., Fig. 11), consistent with the slowing of the glider's forward speed being the largest effect of biofouling. The along-glider change in vertically averaged current increased from $-0.02 \mathrm{~m} \mathrm{~s}^{-1}$ at the beginning of the mission to more than $0.06 \mathrm{~m} \mathrm{~s}^{-1}$ before the loss of accumulated biofouling at dive 350 . The series of vertically averaged current estimates shown in Fig. 11a encompass the abrupt loss of accumulated biofouling at dive 350; after this dive (the southernmost portion of the track shown), corrections to the vertically averaged currents are less pronounced. This portion of the glider's trajectory crosses the eastwardflowing Equatorial Undercurrent. After corrections for biofouling, the vertically averaged currents are more uniform in direction and have a small southward component that is consistent with the Equatorial Undercurrent veering southward around the Galápagos Islands approximately $150 \mathrm{~km}$ downstream of the sampling location (Fig. 4b).

\section{b. Absolute current profiles}

We now focus on estimating profiles of absolute horizontal velocity by combining AD2CP-based measurements of water velocity relative to the moving glider with absolute references. In section $3 b(1)$, we revisit the inverse technique for estimating absolute velocity profiles, which is based on the lowered ADCP (LADCP) methodology of Visbeck (2002) and was previously 

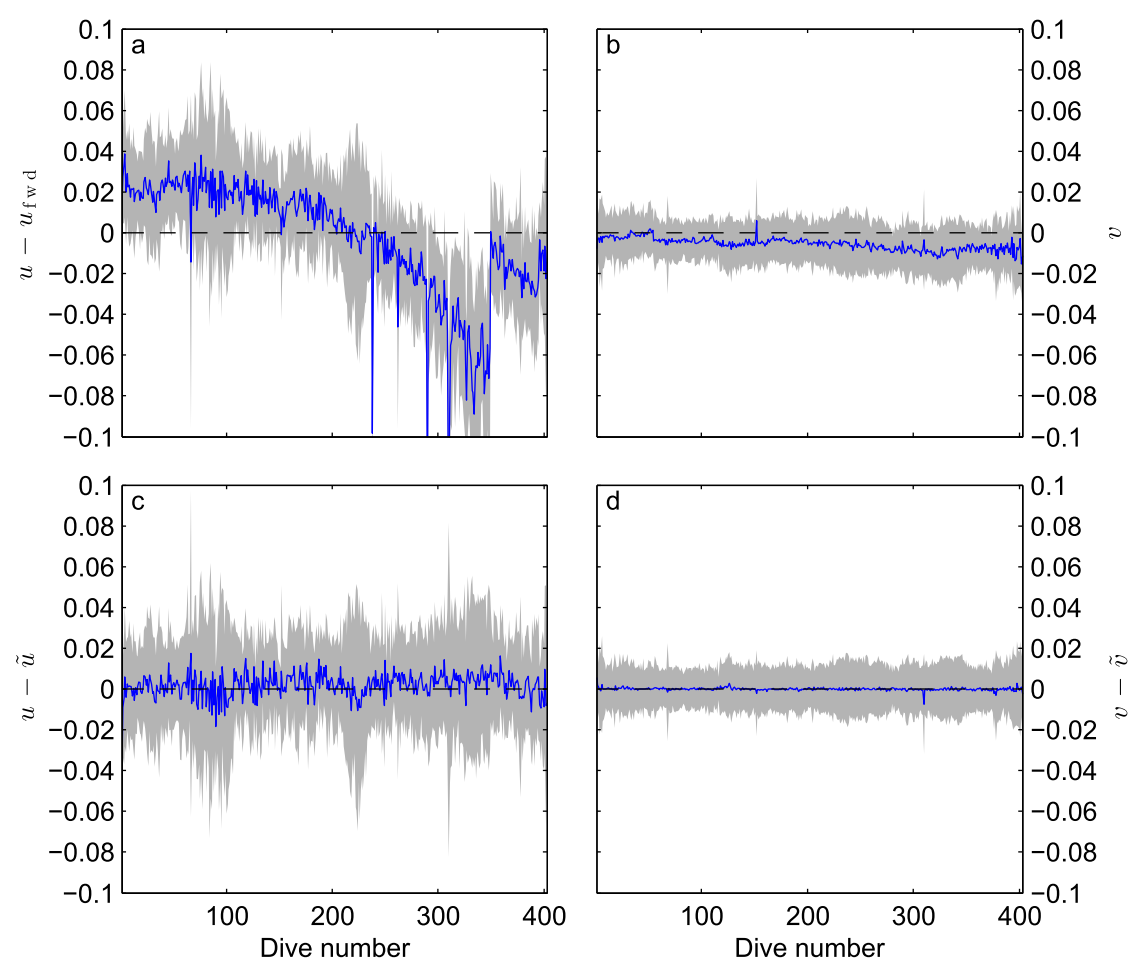

FIG. 10. Differences between AD2CP-derived and flight model-derived estimates of a glider's horizontal velocity as in Fig. 7, but for mission 152058 west of the Galápagos, which exhibited heavy biofouling.

described by Todd et al. (2011b, their appendix B) for the Sontek ADP setup on Spray gliders; we include a complete description of the methodology for completeness and expand upon our previous descriptions by including additional constraints. We note that Davis (2010) explores an alternative method using objective mapping to construct shear profiles over the glider dive depth that yields similar final profiles. In sections $3 b(2)$ and $3 b(3)$, we correct for instrumental bias and evaluate profile accuracy.

\section{1) INVERSE METHOD AND ABSOLUTE CONSTRAINTS}

Relative velocity measurements by the $\mathrm{AD} 2 \mathrm{CP}$ are the difference between the water velocity at the measurement locations and the glider's velocity at the corresponding sampling times. Thus, each valid measurement of horizontal velocity relative to the glider $(u, v)_{r}$ may be expressed as

$$
(u, v)_{r}=(u, v)_{w}-(u, v)_{g},
$$

where $(u, v)_{w}$ is the ocean velocity at the location of the measurement cell and $(u, v)_{g}$ is the velocity of the glider at the same moment. For an ascending profile with $N$ eightping ensembles each returning relative velocity estimates in 15 measurement cells, we have as many as $120 \mathrm{~N}$ equations of the form of (3); exclusion of data as described in section $2 c$ typically reduces the number of equations by about $80 \%$ (e.g., Fig. 3). We have $N$ unknown glider velocities at the sampling times. In the eastward direction, we write the estimated velocity profile as

$$
\left[\begin{array}{llll}
u_{w, 0} & u_{w, 1} & \cdots & u_{w, M}
\end{array}\right]^{\mathrm{T}}
$$

where $u_{w, 0}$ is our estimate of surface velocity and $u_{w, 1}, \ldots, u_{w, M}$ are velocity estimates in $M$ regularly spaced bins; northward velocity is written similarly. We choose a final profile resolution of $10 \mathrm{~m}$, which ensures $M<N$, since eight-ping ensembles every $30 \mathrm{~s}$ are typically separated by about $3-4 \mathrm{~m}$ vertically for a glider ascending at approximately $0.1 \mathrm{~m} \mathrm{~s}^{-1}$.

We write the resulting system of equations as a matrix equation of the form $\mathbf{d}=\mathbf{G m}+\mathbf{n}$. The vector $\mathbf{d}=d_{i}$ consists of individual observations of speed relative to the glider in a particular direction; we let $i \in\left[1, n_{\text {samp }}\right]$ be an index of observations with $n_{\text {samp }}$ as the total number of valid measurements. The vector of unknown glider and water velocities over the ground $\mathbf{m}$ is written as

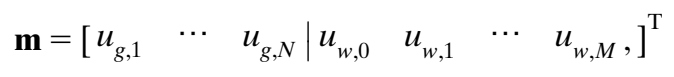

for the eastward velocity. Each row of the corresponding coefficient matrix $\mathbf{G}$ has two nonzero entries. For the $i$ th 

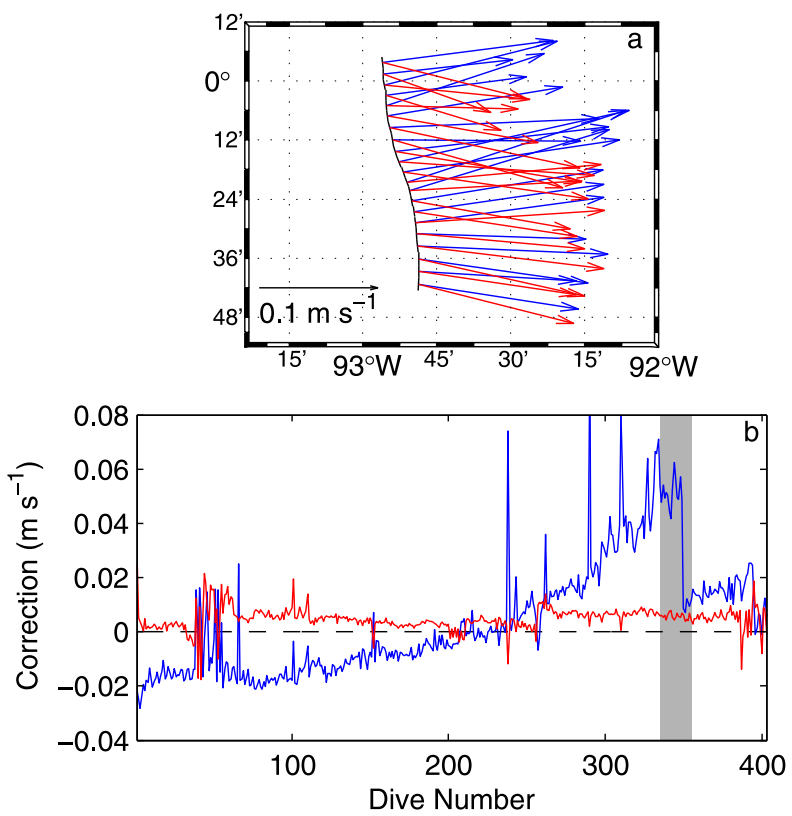

FIG. 11. Corrections to vertically averaged velocity estimates for mission 152058 west of the Galápagos. (a) Vertically averaged current estimates before (blue) and after (red) corrections for angle of attack and sideslip (Fig. 8) for dives 335-355 when the glider was headed southward. (b) Changes in magnitude of vertically averaged current parallel (blue) and perpendicular (red) to the glider's mean heading for each dive after corrections; positive changes are forward and toward the glider's port side.

observation taken during the $j$ th eight-ping ensemble $(j \in[1, N])$ and falling in the $k$ th final velocity profile bin $\left(k \in[1, M]\right.$; the surface bin $u_{w, 0}$ is taken to have zero vertical extent), the elements of $\mathbf{G}$ are $G_{i, j}=-1$ and $G_{i, N+k}=1$. Figure 5 in Visbeck (2002) provides a graphical representation of the coefficient matrix $\mathbf{G}$ for the LADCP inverse problem; our coefficient matrix is similar to the "upcast" portion of Visbeck's. The vector n represents noise from both measurements and an

$$
\frac{C}{z_{M-m}} \times\left[\begin{array}{lll}
0 & \cdots & 0
\end{array} \mid \frac{z_{1}}{2} \quad \frac{z_{1}}{2}+\frac{\Delta z}{2}\right.
$$

The above expression is obtained by approximating the average value of the velocity profile between the surface and the glider's maximum dive depth using the trapezoidal rule with $z_{1}$ being the depth of the midpoint of the first bin with AD2CP data, $\Delta z=10 \mathrm{~m}$ being the vertical extent of the bins, and $C$ being a constant that ensures the $L^{2}$ norm of the constraint equation is unity. Only the $M-m$ bins encompassing the glider's profile range are included in the vertically averaged velocity constraint; $m$ deeper imperfectly estimated velocity field. Though this system of $N+M+1<2 N$ unknowns and many more than $2 N$ equations is formally overdetermined, as discussed by Visbeck (2002) and Todd et al. (2011b), the AD2CP measurements can give only the baroclinic portion of the velocity profile; additional constraints on the absolute velocity are required. Following Visbeck (2002) and Todd et al. (2011b), we also include a curvatureminimizing smoothness constraint to both the glider and water velocities with multiplicative weight $w_{\text {smooth }}=1$; this constraint allows for small gaps due to bad AD2CP data to be circumvented, but it does not help to constrain absolute velocity. With the addition of suitable absolute velocity constraints, the solution for the unknown absolute velocities is obtained by least squares as

$$
\mathbf{m}=\left(\mathbf{G}^{\mathrm{T}} \mathbf{G}\right)^{-1} \mathbf{G}^{\mathrm{T}} \mathbf{d} .
$$

Some velocity profiles resulting from (6) are outliers and are rejected from further analysis. Many of these outliers result when the matrix $\mathbf{G}$ is poorly conditioned (e.g., due to too few data), so we require that at least $90 \%$ of the final velocity bins for a given profile contain $\mathrm{AD} 2 \mathrm{CP}$ measurements before attempting to compute a velocity profile. Velocity profiles are subsequently compared to the preceding and following 10 profiles and discarded if they fall more than 2.5 standard deviations from the mean of surrounding profiles.

In our previous work with both glider-based Doppler velocity measurements and geostrophic calculations, we have relied on the glider-based estimate of vertically averaged current (i.e., section $3 a$ ) as the sole absolute velocity reference. For the inverse velocity solution considered here, that constraint is included as an additional equation with the added row to $\mathbf{G}$ having the form

$\left.\Delta z \quad \cdots \quad \Delta z \quad \frac{\Delta z}{2} \quad 0 \quad \cdots \quad c\right]$

bins are excluded. The corresponding element added to $\mathbf{d}$ is $C U$, where $U$ is the estimated vertically averaged velocity (i.e., section $3 a$ ). When vertically averaged velocity is the sole absolute constraint, surface velocity $\left(u_{w, 0}\right)$ is constrained to match the velocity in the first bin with AD2CP data.

We consider various constraints on absolute velocity using mission 15A065 in the Gulf Stream. When the vertically averaged velocity constraint $[(7)]$ is the only constraint on the absolute velocity, it is met exactly 

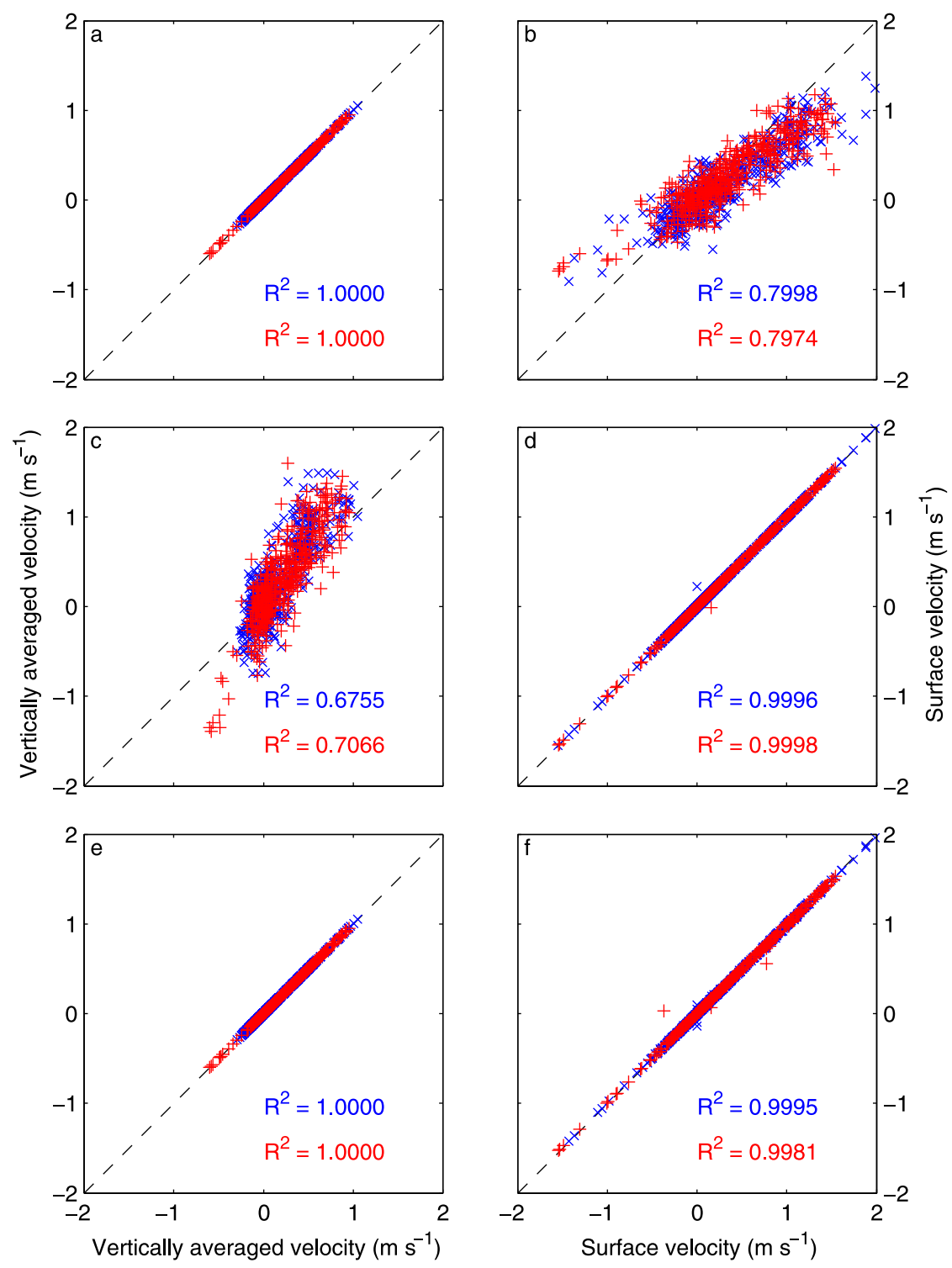

FIG. 12. Scatterplots of (left) vertically averaged velocities and (right) near-surface velocities for mission 15A065 in the Gulf Stream with the horizontal axis showing the gliderbased measurement and the vertical axis showing the corresponding value from the AD2CP-derived velocity profile. Scatterplots are shown when (a),(b) only the vertically averaged current constraint is applied, (c),(d) only the surface velocity constraint is applied, and (e),(f) when both the vertically averaged velocity and surface velocity are constrained. Blue (red) points and skill values $\left(R^{2}\right)$ correspond to eastward (northward) velocity components, and the dashed black lines indicate one-to-one correspondence.

(e.g., Fig. 12a). For a northbound transect across the Gulf Stream (Fig. 4c), application of only the vertically averaged velocity constraint yields velocity solutions (Figs. 13a and 13b) that show the expected strong northeastward velocity of the Gulf Stream near $35^{\circ} \mathrm{N}$ as it separates from the continental margin and weaker flow on either side of the Gulf Stream. However, these velocity estimates exhibit notably large profile-to-profile variability and a lack of surface intensification in the eastward velocity that seem unrealistic.

A possible additional absolute velocity constraint is the surface velocity estimated from glider drift during the time between consecutive postdive and predive GPS fixes, typically about $5 \mathrm{~min}$. For a conservative GPS accuracy of $15 \mathrm{~m}$ and a surface drift time of $300 \mathrm{~s}$, we may expect estimates of surface drift speed to be accurate to 

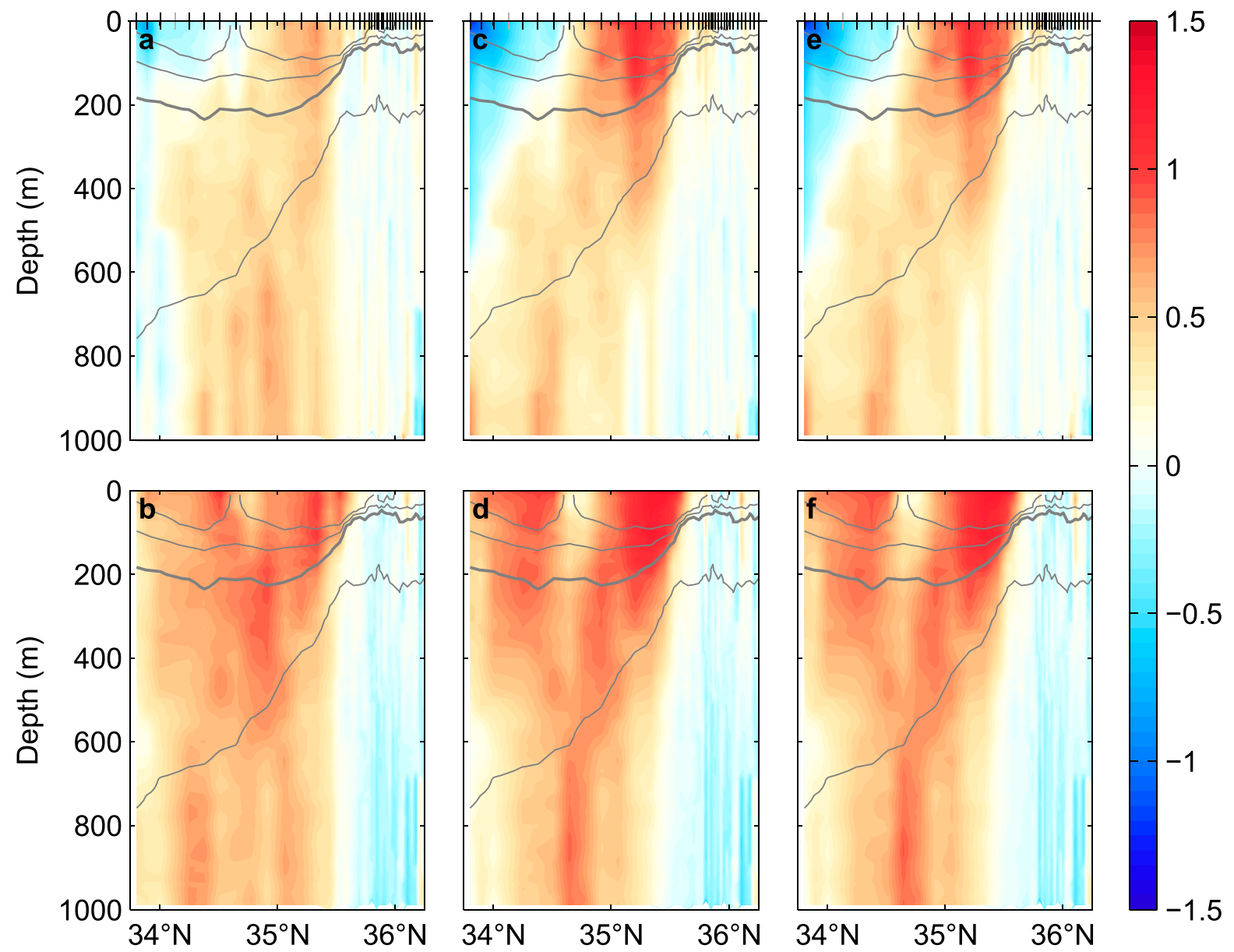

FIG. 13. Absolute velocity estimates along a transect across the Gulf Stream from mission 15A065. (a),(c),(e) Eastward and (b),(d),(f) northward velocity as a function of depth and latitude are shown for solutions with (a),(b) only a vertically averaged velocity constraint, (c),(d) both a vertically averaged velocity and surface constraint, and (e),(f) both constraints and corrections for shear bias. Gray contours are isopycnals with a contour interval of $1 \mathrm{~kg} \mathrm{~m}^{-3}$, and the bold line is the $26 \mathrm{~kg} \mathrm{~m}^{-3}$ isopycnal. Tick marks on the upper axes denote the locations of individual profiles; note that one profile (denoted by a gray tick near $34.1^{\circ} \mathrm{N}$ ) has been omitted due to a poor velocity solution. The location of the transect is highlighted in Fig. 4c.

within $0.05 \mathrm{~m} \mathrm{~s}^{-1}$. Figure $12 \mathrm{~b}$ compares measured surface drift velocities during mission $15 \mathrm{~A} 065$ with the surface velocities from the AD2CP-derived velocity profiles computed with the vertically averaged current constraint $[(7)]$ being the only absolute constraint. Agreement between these two independent estimates of surface velocity is good with squared correlation coefficients exceeding 0.79 and root-mean-square (RMS) differences of $0.40 \mathrm{~m} \mathrm{~s}^{-1}$ when surface current speeds ranged as high as $2.3 \mathrm{~m} \mathrm{~s}^{-1}$. Surface speeds are typically underestimated in these estimated profiles, consistent with the lack of surface intensification in Figs. 13a and 13b.

As an alternative to using the vertically averaged velocity constraint, use of only the near-surface velocity estimate as an absolute velocity constraint yields a well-posed problem. The constraint is applied by adding a single equation that states that the surface velocity estimate $u_{w, 0}$ from the inverse solution is equal to the surface velocity estimate from glider drift; the added row to $\mathbf{G}$ is simply

$$
\left[\begin{array}{llllll}
0 & \cdots & 0 \mid 1 & 0 & \cdots & 0
\end{array}\right]
$$

and the corresponding element of $\mathbf{d}$ is $u_{\text {surf }}$, the estimated surface drift velocity. Since the surface velocity bin is taken to have zero vertical extent and the downwardlooking AD2CP does not sample exactly at the surface, we rely on the smoothness constraint to couple the surface drift estimate to the velocity profile in the absence of the vertically averaged velocity constraint. Figures $12 \mathrm{c}$ and $12 \mathrm{~d}$ demonstrate that exactly matching the surface velocity constraint results in the vertical average of the AD2CP-derived velocity profile being 
positively correlated with the glider-based estimate of the vertically averaged currents, but with less skill than for surface velocity estimates when only the vertically averaged velocity constraint is enforced (Fig. 12b). Absolute velocity profiles resulting from application of only the surface velocity constraint tend to exhibit more profile-to-profile variability than those resulting from application of only the vertically averaged velocity constraint (not shown); this is to be expected given the somewhat noisier nature of surface current estimates and their application at a single depth rather than to the entire profile. Nevertheless, surface current estimates appear to provide some useful information for constraining absolute velocity, so we next consider including that information in our velocity solution along with the vertically averaged velocity constraint.

To apply both the vertically averaged velocity and surface velocity constraints in our inverse solution, we must assign weights to the two constraints. These weights are necessary because we should not expect both constraints to be met perfectly, since both absolute velocity estimates may contain errors. The weights are applied as simple multiplicative constants on the corresponding equations [(7) and (8)] in the inverse problem, which have initially equal $L^{2}$ norms (i.e., the squared sum of the elements in each of the two rows of $\mathbf{G}$ is one). For mission $15 \mathrm{~A} 065$, we set the weights for (7) and (8) based on the expected signal-to-noise ratios of vertically averaged and surface current estimates. We take typical vertically averaged velocity and surface drift speeds in the Gulf Stream to be 1 and $2 \mathrm{~m} \mathrm{~s}^{-1}$, respectively. Noise in those estimates are taken to be $0.01 \mathrm{~m} \mathrm{~s}^{-1}$ (Todd et al. 2011b) and $0.05 \mathrm{~m} \mathrm{~s}^{-1}$, respectively. Expected signal-to-noise ratios are then 100 and 40 for vertically averaged currents and surface drift speeds, respectively, so we take the weights to be $w_{\text {avg }}=5$ and $w_{\text {surf }}=2$ for the vertically averaged and surface velocity constraints, respectively.

Applying both absolute velocity constraints for mission 15A065 in the Gulf Stream works well and yields near-perfect correlations between both vertically averaged velocities (Fig. 12e) and surface currents (Fig. 12f) from glider-based estimates and profile-based estimates. For the northbound transect offshore of Cape Hatteras, North Carolina (Fig. 4c), the eastward and northward velocity profiles that result from applying both the vertically averaged current and surface current constraints (Figs. 13c and 13d) exhibit less profile-to-profile variability than the solutions with only the vertically averaged velocity constraint (Figs. 13a and 13b) and show the expected surface intensification of the Gulf Stream. The typically tilted velocity core of the northeastwardflowing Gulf Stream (cf. Halkin and Rossby 1985; Johns et al. 1995; Rossby and Zhang 2001; Todd et al. 2016), a portion of a surface intensified eddy seaward (south) of the Gulf Stream with northwestward velocity in the upper $100 \mathrm{~m}$, and the variable tidally dominated flow north of the Gulf Stream along the continental margin are all readily apparent.

Though application of a surface velocity constraint improved our velocity profile estimates in the Gulf Stream, similar use of a surface velocity constraint leads to increased profile-to-profile variability and overall poorer velocity profile estimates for missions 152057,152058 , and 157030 in the eastern equatorial Pacific and off Southern California (not shown). We attribute this difference in effect of the surface velocity constraint to the local character of surface flow. Since our surface velocity estimates are based on the drift of a glider sitting on the surface with a wing in the air, they are influenced by both Stokes drift and the glider's wing acting as a sail. Additionally, large near-surface shear (e.g., in a thin Ekman layer) may not be well-represented in our solutions, since the glider and AD2CP do not sample the upper few meters of the water column well. In the eastern equatorial Pacific and off Southern California, these influences combine so that surface drift estimates are not good absolute references for our velocity profiles. The Gulf Stream, on the other hand, is surface intensified and has large Eulerian surface velocities that are captured by the surface drift estimates. In choosing whether to use surface velocity estimates to constrain absolute velocity profiles, conditions during a given glider mission must be considered; a comparison to geostrophic currents or other independent measures can aid in the decision-making process.

\section{2) CORRECTING SHEAR BIAS}

Reconstruction of absolute velocity profiles over $O(1000)$ m effectively requires integration of many individual shear profiles of $O(10)$ m extent, so a small shear bias in individual profiles returned by a glider- (or rosette)-mounted Doppler current profiler can result in large velocity errors in the reconstructed profiles. For instance, nominal $0.1 \mathrm{~m} \mathrm{~s}^{-1}$ accuracy over $1000 \mathrm{~m}$ requires individual profiles to have shear bias no larger than $0.001 \mathrm{~m} \mathrm{~s}^{-1}$ over $10 \mathrm{~m}$. Achieving such high accuracy in individual profiles is a technical challenge. On the other hand, the finescale $(10-100-\mathrm{m}$ scale) structure in reconstructed profiles is obtained from fewer profiles and typically has a larger oceanic signal, so it is less affected by small shear bias in individual profiles.

Examination of velocity profile estimates from many Spray glider missions with AD2CPs reveals that the AD2CPs often produce biased shear estimates. Missions 157030 off Southern California and 152058 in the eastern equatorial Pacific exemplify this behavior. 
Figures 14 and 15 show successive transects of cross-track (Figs.14a-d and 15a-d) and along-track (Figs.14i-1 and 15i-1) velocity estimates for missions 157030 and 152058, respectively, that result from application of only a vertically averaged velocity constraint. Most clearly in the along-track velocity estimates, these velocity estimates exhibit large magnitudes near the gliders' maximum profiling depths that change sign as the gliders change direction on successive transects. Such heading-dependent signals are clearly artificial.

Since the gliders deployed on missions 152058 and 152057 crossed paths three times (Fig. 4) while heading in opposite directions, we have independent estimates of velocity profiles that can be used to better characterize the behavior of our velocity solution at depth. Table 1 gives the approximate latitude of these crossings and the temporal and spatial separation between the nearest dives. Figure 16 shows the mean and standard deviation of eastward and northward velocity averaged over the five profiles from each glider nearest to the three crossings. For our initial velocity solutions (left-hand profiles in each panel of Fig. 16, corresponding to Figs. 15a-d and 15i-1), the root-mean-square difference between the mean profiles from the two gliders ranged from 0.10 to $0.13 \mathrm{~m} \mathrm{~s}^{-1}$ (Table 1). These differences are dominated by the differences in northward (approximately along track) velocity between the two gliders. Northward velocity profiles from mission 152058 (red) tend to deviate in the opposite direction of each glider's heading at depth (e.g., large southward velocity near $1000 \mathrm{~m}$ during the first crossing when that glider was headed northward). Despite the differences in absolute magnitude, particularly for northward velocity, the velocity profiles from the two independent gliders exhibit similar finescale structure, particularly in the upper half of the profiles.

To better characterize the observed shear bias, we have closely examined along-beam velocities from many Spray glider missions with AD2CPs. Figure 17 shows mean along-beam velocity profiles for the four glider missions considered here. If a glider's orientation relative to currents is effectively random over an entire mission, then we expect these mean profiles to exhibit no preferred shear. Use of current-bucking navigation modes may violate this assumption, particularly for the aft-looking beam 1 . Nevertheless, it is clear from Fig. 17 that each transducer on each instrument behaves differently. Along-beam velocities from beam 1, which sees the largest mean alongbeam velocities, typically exhibit the largest bias and are likely the leading contributor to bias in estimated current profiles. It is important to note that these biases are quite small, typically less than $0.01 \mathrm{~m} \mathrm{~s}^{-1}$ over $10 \mathrm{~m}$ (five $2-\mathrm{m}$ cells). However, integration of such a small bias over a profile of $O(1000) \mathrm{m}$ amounts to an error of $O(1) \mathrm{m} \mathrm{s}^{-1}$ in the velocity magnitudes (e.g., profiles from mission 152058 shown in red in Fig. 16). We do not yet know the source of these small biases, but we continue to work with the instrument manufacturer to minimize them.

Since velocity profile estimates from our inverse solution have a large-scale (profile-scale) shear bias but show realistic finescale structure, we seek to correct these profiles by subtracting a linear velocity profile. The linear velocity profile should have a vertical average of zero so that our vertically averaged velocity constraint $[(7)]$ is not violated; for solutions that additionally enforce a surface velocity constraint (e.g., mission 15A065), the surface constraint will no longer be met exactly. We assume that the shear bias is constant for a given glider mission, so we remove the same shear from all the profiles. Since the bias is heading dependent, we apply our correction in the along- and cross-glider directions rather than in geographic coordinates. Once an optimal velocity profile is determined for each mission, each velocity profile is rotated into along- and cross-glider components using the mean heading during the ascending portion of the glider's dive. A zero-mean linear velocity profile is then subtracted. The corrected profiles are then rotated back into geographic coordinates.

To determine the optimal velocity profiles to remove, we seek to minimize the variance in our velocity solutions. Since the shear bias is instrument dependent, the bias introduces artificial variance as the glider changes heading during a mission. We compute profiles of the variance of complex velocity $(u+i v)$ using the uncorrected velocity estimates from each glider mission (e.g., Figs. 13c,d, 14a-d,i-1, and 15a-d,i-1). These variance profiles (Fig. 18, dashed lines) exhibit minima at middepth (Fig. 18, dotted black lines); we denote this depth $z_{0}$ (Table 2). High variance in the upper few hundred meters is to be expected due to oceanic variability, but we expect a general decrease in velocity variance with depth. Increasing variance with depth in our velocity solutions in the lower part of the sampled water column is due to the combination of the shear bias and random errors (see below). For each glider mission, we seek to minimize the velocity variance below $z_{0}$ by correcting for shear bias. Constant along- and crossglider shear biases are found via standard nonlinear multidimensional minimization techniques (fminsearch in MATLAB). Values of the shear biases vary by mission (Table 2); biases exceed $0.10 \mathrm{~m} \mathrm{~s}^{-1} \mathrm{~km}^{-1}$ only in the along-glider direction for missions 157030 and 152058 , consistent with the large bias in beam 1 (Fig. 17).

Mission 15A065 was minimally affected by shear bias (Table 2), and our correction has little effect on either the profile of velocity variance (Fig. 18d, solid black line 

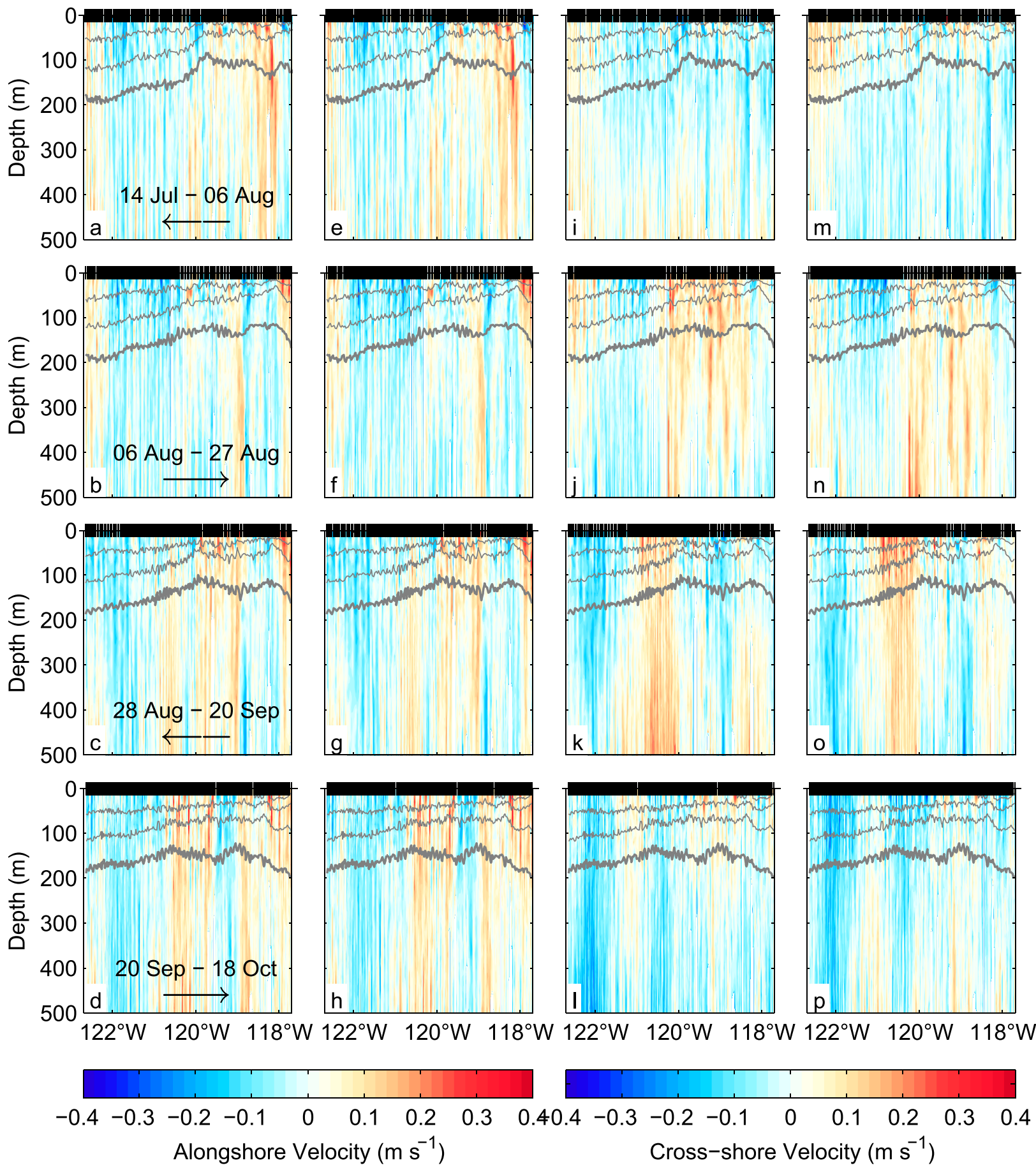

FIG. 14. Estimates of absolute velocity from four successive cross-shore transects off Southern California during mission 157030. Both (a)-(h) alongshore (positive poleward) and (i)-(p) cross-shore (positive onshore) velocity estimates are shown (a)-(d),(i)-(l) before and $(\mathrm{e})-(\mathrm{h}),(\mathrm{m})-(\mathrm{p})$ after correcting for shear bias. Gray contours are isopycnals with a contour interval of $1 \mathrm{~kg} \mathrm{~m}^{-3}$, and the bold line is the $26 \mathrm{~kg} \mathrm{~m}^{-3}$ isopycnal. Tick marks on the upper axes denote the locations of individual profiles. Arrows in (a)-(d) denote the direction of glider travel during the dates shown. 

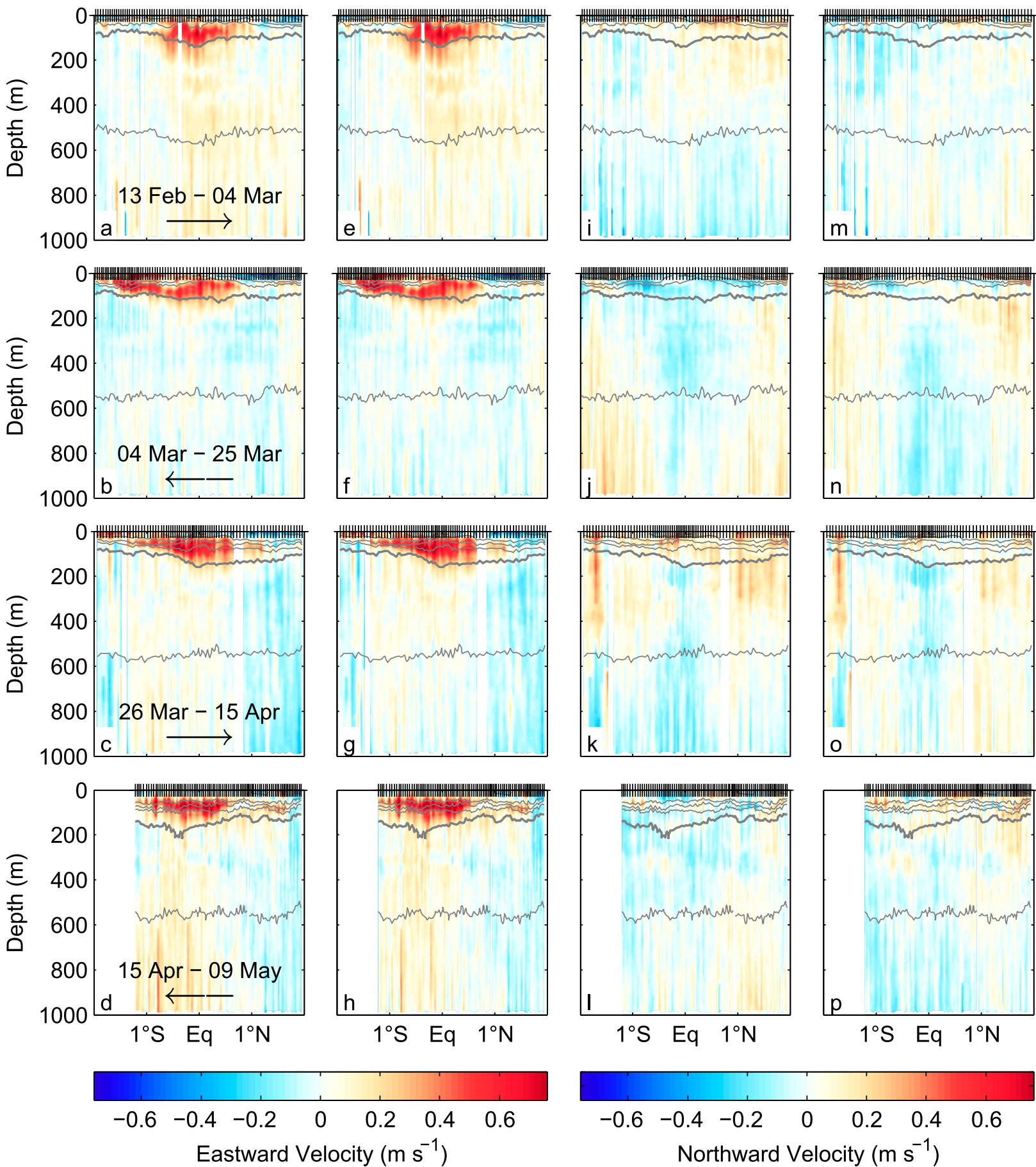

FIG. 15. Estimates of absolute velocity from four successive transects across the equator along $93^{\circ} \mathrm{W}$ during mission 152058 . Both (a)-(h) eastward and (i)-(p) northward velocity estimates are shown (a)-(d),(i)-(l) before and (e)-(h),(m)-(p) after correcting for shear bias. Gray contours are isopycnals with a contour interval of $1 \mathrm{~kg} \mathrm{~m}^{-3}$, and the bold line is the $26 \mathrm{~kg} \mathrm{~m}^{-3}$ isopycnal. Tick marks on the upper axes denote the locations of individual profiles. Gaps in the transects are due to profiles for which the velocity solution was rejected. Arrows in (a)-(d) denote the direction of glider travel during the dates shown. 
TABLE 1. Statistics associated with the three instances when gliders crossed paths during missions 152057 and 152058 . Latitudes of the four crossings are as depicted in Fig. 4b. Temporal and spatial separations are between the midpoints of the nearest dives. RMS differences are between the pairs of mean profiles shown in Fig. 16.

\begin{tabular}{|c|c|c|c|c|c|}
\hline Crossing & Lat & $\begin{array}{c}\text { Temporal } \\
\text { separation }(\mathrm{min})\end{array}$ & $\begin{array}{c}\text { Spatial } \\
\text { separation }(\mathrm{km})\end{array}$ & $\begin{array}{l}\text { RMS difference before } \\
\text { correction }\left(\mathrm{m} \mathrm{s}^{-1}\right)\end{array}$ & $\begin{array}{l}\text { RMS difference after } \\
\text { correction }\left(\mathrm{m} \mathrm{s}^{-1}\right)\end{array}$ \\
\hline 1 & $1.0^{\circ} \mathrm{N}$ & 12 & 6.6 & 0.12 & 0.09 \\
\hline 2 & $1.1^{\circ} \mathrm{S}$ & 68 & 5.0 & 0.13 & 0.07 \\
\hline 3 & $0.9^{\circ} \mathrm{N}$ & 215 & 3.3 & 0.10 & 0.07 \\
\hline
\end{tabular}

overlaying the dashed line) or the example transect across the Gulf Stream (Figs. 13e and 13f). Mission 152057 was similarly unaffected by shear bias (Fig. 18b, Table 2). For missions 157030 and 152058 , velocity variance below $z_{0}$ is reduced (Figs. 18a and 18c, respectively) as intended, and obvious heading-dependent signals in the velocity estimates are eliminated (Fig. 14e-h and $\mathrm{m}-\mathrm{p}$, and $15 \mathrm{e}-\mathrm{h}$ and $\mathrm{m}-\mathrm{p}$, respectively), particularly in the along-track

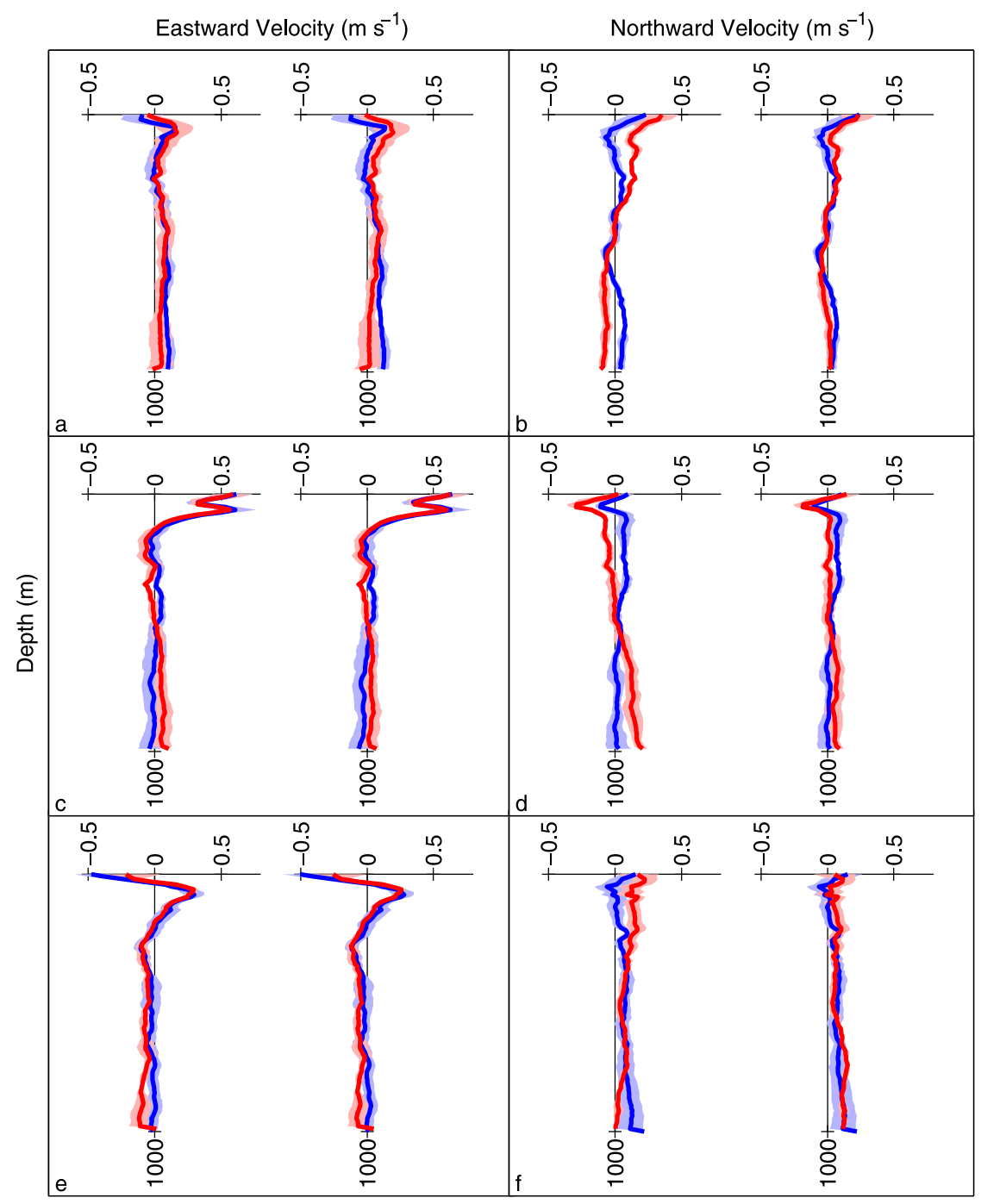

FIG. 16. Comparisons of absolute velocity profiles from missions 152057 (blue) and 152058 (red) when the two gliders crossed paths. Profiles are shown before (left in each panel) and after (right in each panel) correcting for shear bias. (a),(c),(e) Eastward and (b),(d),(f) northward velocity comparisons are shown for the (a),(b) first crossing, (c),(d) second crossing, and (e),(f) third crossing. Bold profiles are the average of the five profiles from each mission nearest to the crossing with shading indicating the standard deviation between profiles. 

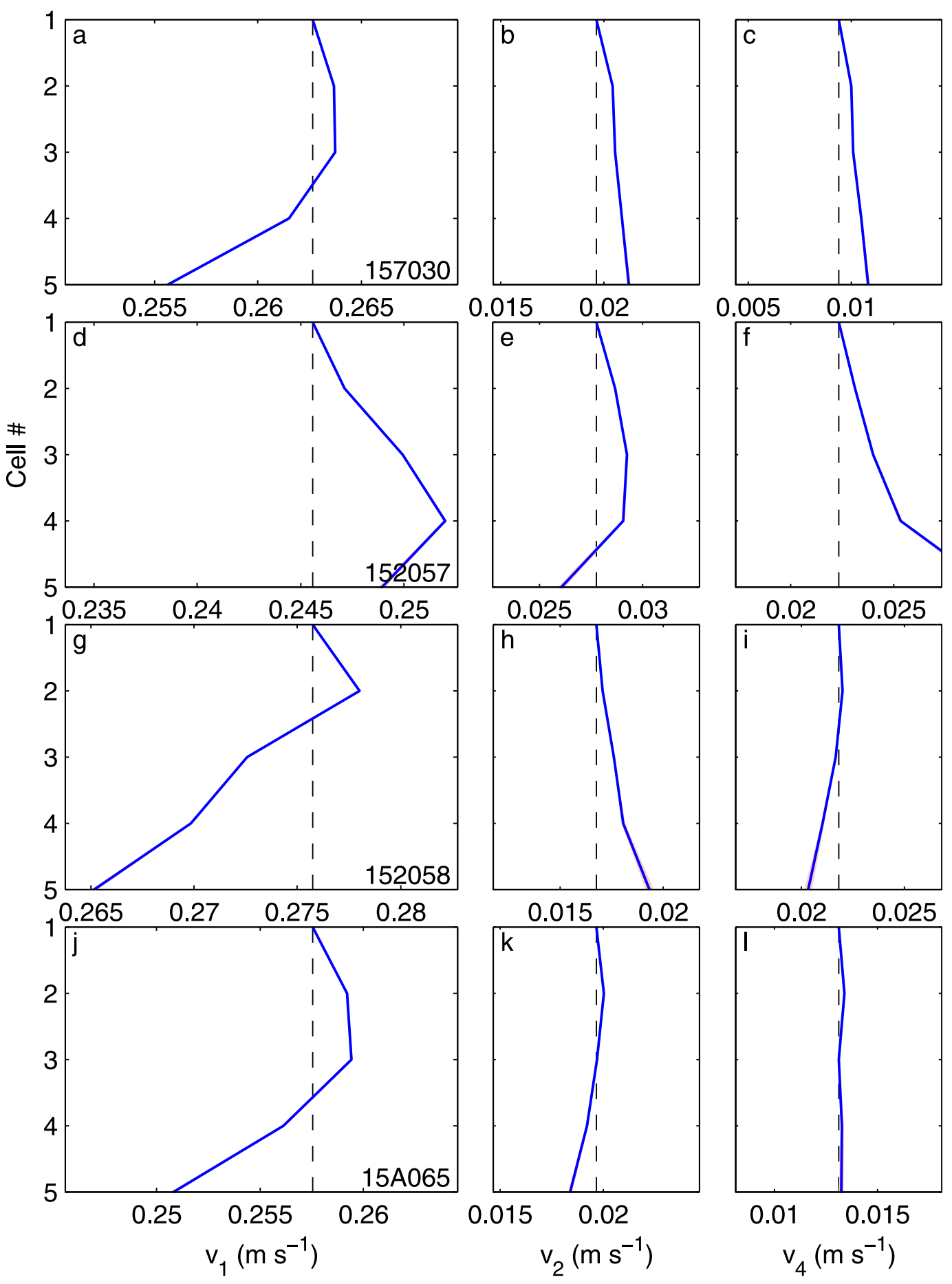

FIG. 17. Mean along-beam velocity profiles for the four glider missions (blue). Along-beam velocities for the (left) aft-looking beam $1\left(v_{1}\right)$, (middle) starboard-looking beam $2\left(v_{2}\right)$, and (right) port-looking beam $4\left(v_{4}\right)$ are shown with means calculated using only AD2CP data that pass quality control checks. Standard error of the mean is indicated by red shading but is approximately the thickness of the line. Note that each velocity axis has different values, but that the ranges are constant across missions for each beam and that all axes have equivalent scaling. Dashed black lines indicate the mean velocity in the measurement cell nearest to the glider. 


\section{$1-\mathrm{MHz}$ Acoustic Backscatter (dB)}
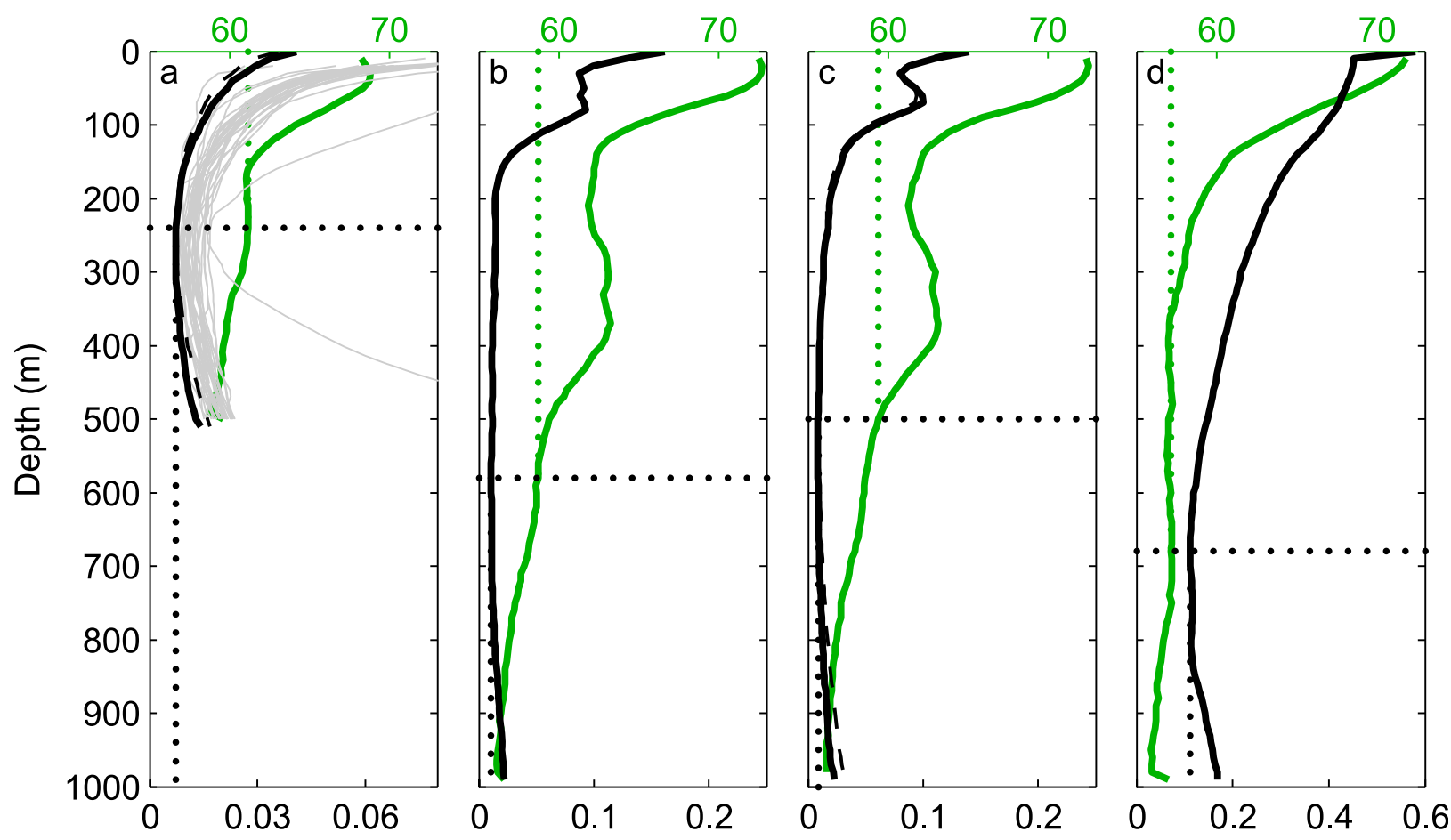

\section{Velocity Variance $\left(\mathrm{m}^{2} \mathrm{~s}^{-2}\right)$}

FIG. 18. Profiles of velocity variance (black) and mean acoustic backscatter (green) for missions (a) 157030, (b) 152057, (c) 152058, and (d) 15A065. Dashed variance profiles are from velocity estimates without corrections for shear bias; solid variance profiles are from velocity estimates with corrections for shear bias. In (b) and (d), the solid variance profile overlies the dashed profile. Black dotted lines indicate the depth and magnitude of the minimum in velocity variance before corrections for shear bias; the depth of this minimum is the depth below which variance is minimized to determine the correction for shear bias. Dotted green lines indicate the mission-averaged backscatter intensity at the depth of the variance minimum. In (a), gray variance profiles are from 32 Spray glider missions off Southern California with Sontek ADPs.

component of the velocity. For mission 157030 off Southern California, transects of eastward and northward velocity (e.g., Fig. 14e-h,m-p) show familiar features of the circulation in the southern California Current System (cf. Todd et al. 2011b, and references therein), such as the surface-intensified, equatorward-flowing California Current centered near $121^{\circ} \mathrm{W}$ and poleward flow near the surface along the coast (east of $118^{\circ} \mathrm{W}$ ). For mission 152058 west of the Galápagos, the eastward-flowing Equatorial Undercurrent is apparent in each transect with substantial transect-to-transect variability in location and structure (Figs. 15e-h,m-p). For all missions, highfrequency variability from internal waves manifests as high-wavenumber (i.e., dive-to-dive) variability in both absolute currents and isopycnal depth (cf. Johnston and Rudnick 2015). Comparisons between independent velocity profile estimates from the instances when the two gliders crossed paths during missions 152057 and 152058 are improved following the corrections for shear bias
(Fig. 16, right-hand profiles in each panel). Root-meansquare differences between mean profiles are reduced to $0.07-0.09 \mathrm{~m} \mathrm{~s}^{-1}$ (Table 1), with northward (approximately along-track) differences still dominating.

\section{3) ACCURACY CONSIDERATIONS}

We now consider the overall accuracy of our velocity estimates. The accuracy of our vertically averaged velocity estimates limits the absolute accuracy of our AD2CPderived velocity profiles. Using data from many glider missions off the California coast, we have previously shown that vertically averaged velocity estimates from Spray gliders have a typical uncertainty of $0.01 \mathrm{~m} \mathrm{~s}^{-1}$ for a single estimate (Todd et al. 2011b).

Profiles of velocity variance for each mission (Fig. 18) allow us to begin quantifying the accuracy of our AD2CP-derived velocity profiles. Visbeck (2002) notes that for an LADCP system with an integral absolute constraint akin to our vertically averaged velocity 
TABLE 2. Parameters associated with the shear bias and velocity variance for each glider mission. Depth of minimum velocity variance $z_{0}$; along- and cross-glider shears removed to correct for bias; standard deviation of vertically averaged velocity STD(U); standard deviation of velocity at $z_{0} \operatorname{STD}\left[\mathbf{u}\left(z_{0}\right)\right]$; and maximum RMS error below $z_{0}$ are given for each mission.

\begin{tabular}{lcccccc}
\hline \hline Mission & $z_{0}(\mathrm{~m})$ & $\begin{array}{c}\text { Along-glider shear } \\
\left(\mathrm{m} \mathrm{s}^{-1} \mathrm{~km}^{-1}\right)\end{array}$ & $\begin{array}{c}\text { Cross-glider shear } \\
\left(\mathrm{m} \mathrm{s}^{-1} \mathrm{~km}^{-1}\right)\end{array}$ & $\mathrm{STD}(\mathbf{U})\left(\mathrm{m} \mathrm{s}^{-1}\right)$ & $\mathrm{STD}\left[\mathbf{u}\left(z_{0}\right)\right]\left(\mathrm{m} \mathrm{s}^{-1}\right)$ & ${\mathrm{RMS} \mathrm{error} \mathrm{below} z_{0}\left(\mathrm{~m} \mathrm{~s}^{-1}\right)}^{0}$ \\
\hline 157030 & 240 & -0.25 & 0.00 & 0.08 & 0.09 & 0.08 \\
152057 & 580 & 0.00 & -0.05 & 0.08 & 0.10 & 0.11 \\
152058 & 500 & -0.25 & 0.00 & 0.08 & 0.09 & 0.12 \\
15 A065 & 680 & 0.01 & 0.08 & 0.41 & 0.33 & 0.24 \\
\hline
\end{tabular}

constraint, minimum error is to be expected near the midpoint of the velocity profile with increasing error toward the top and bottom of the profile. For missions 157030 and $152058, z_{0}$ lies very near the midpoint of the profiles (Table 2). For mission 152057, $z_{0}$ is somewhat deeper, but the variance is approximately constant at depths from 200 to $700 \mathrm{~m}$ (Fig. 18b). For mission 15A065 in the Gulf Stream, $z_{0}$ is deeper than the midpoint of the profile, presumably due to the very large variability in currents at all sampled depths. Errors in AD2CPderived shear contribute to larger variability above and below $z_{0}$. We anticipate that random errors in individual $\mathrm{AD} 2 \mathrm{CP}$ measurements grow with depth as acoustic scatterers become less prevalent (Fig. 18, green profiles). To meet the vertically averaged velocity constraint for a particular profile, random errors at the bottom of the profile are balanced by oppositely signed errors near the top of the profile, resulting in larger velocity variance at the top and bottom of the profile (Fig. 18). The variance in AD2CP-derived velocity profiles off Southern California (Fig. 18a, black profile) is comparable to the variance in velocity profiles from 32 Spray glider missions along the same survey line (Fig. 18a, gray profiles) that carried the older Sontek current profilers (see Davis 2010; Todd et al. 2011b).

The amount of additional velocity variance below $z_{0}$ provides a measure of the (presumably) random error due to reduced scatterers at depth. Note that missionaveraged acoustic backscatter steadily decreases below $z_{0}$ for each mission (Fig. 18), suggesting that AD2CP performance should decline below $z_{0}$. Table 2 gives the square root of the difference between the variance at $z_{0}$ and the maximum variance below $z_{0}$ as an estimate of the RMS error at the bottom of individual profiles for each mission. These errors range from $0.08 \mathrm{~m} \mathrm{~s}^{-1}$ for the profiles to $500 \mathrm{~m}$ during mission 157030 off Southern California to $0.24 \mathrm{~m} \mathrm{~s}^{-1}$ for mission 15A065, which encountered particularly poor scattering conditions seaward of the Gulf Stream (e.g., Fig. 1c). Given the size of these estimated errors, combining adjacent profiles through averaging, objective mapping, or similar techniques may be prudent; if the remaining errors are indeed random, then error reduction is proportional to the square root of the number of profiles combined. For example, Fig. 19 shows the result of objectively mapping velocities from the 14-25 March 2015 transect along $93^{\circ} \mathrm{W}$ from mission 152058 (Figs. $15 \mathrm{f}$ and $15 \mathrm{n}$ ) using a Gaussian covariance matrix with a $30-\mathrm{km}$ length scale (Todd et al. 2011b). For the 1000-m dives of mission 152058 , roughly 10 profiles are contained within one length scale of a given along-track location, so this mapping effectively combines about 10 profiles and should reduce errors by approximately a factor of 3 .

Away from the equator, we can also compare our AD2CP-based velocity estimates to geostrophic velocity estimates. As discussed in Todd et al. (2011b), such comparisons are valid only at horizontal and temporal scales at which a geostrophic balance is expected to hold; profile-to-profile variability is strongly influenced by high-frequency variability (e.g., internal waves) that is not in geostrophic balance. For one transect off Southern California from mission 157030, smoothing the AD2CP-derived velocity fields horizontally (Fig. 20a) allows for comparison with crosstrack (alongshore) geostrophic velocity (Fig. 20b). Above $300 \mathrm{~m}$, regressions of geostrophic velocity on AD2CP velocities yield skills and gains exceeding 0.8 , indicating good agreement between the two estimates at spatial scales larger than $30 \mathrm{~km}$ (Fig. 20c); below $300 \mathrm{~m}$, both skills and gains decrease with depth. For mission $15 \mathrm{~A} 065$ in the Gulf Stream, regressions between smoothed cross-track velocity estimates from the AD2CP (Fig. 21a) and cross-track geostrophic velocities (Fig. 21b) have skills near 0.8 and gains of 0.8 to near 1.0 above $650 \mathrm{~m}$ and decreasing agreement below $650 \mathrm{~m}$. The depths at which the AD2CP-derived velocities begin to diverge from geostrophic velocities correspond to the depth at which variance in the velocity solutions begins to increase (Fig. 18).

\section{Summary and conclusions}

Doppler current profilers carried onboard autonomous underwater gliders provide measurements of water velocity 

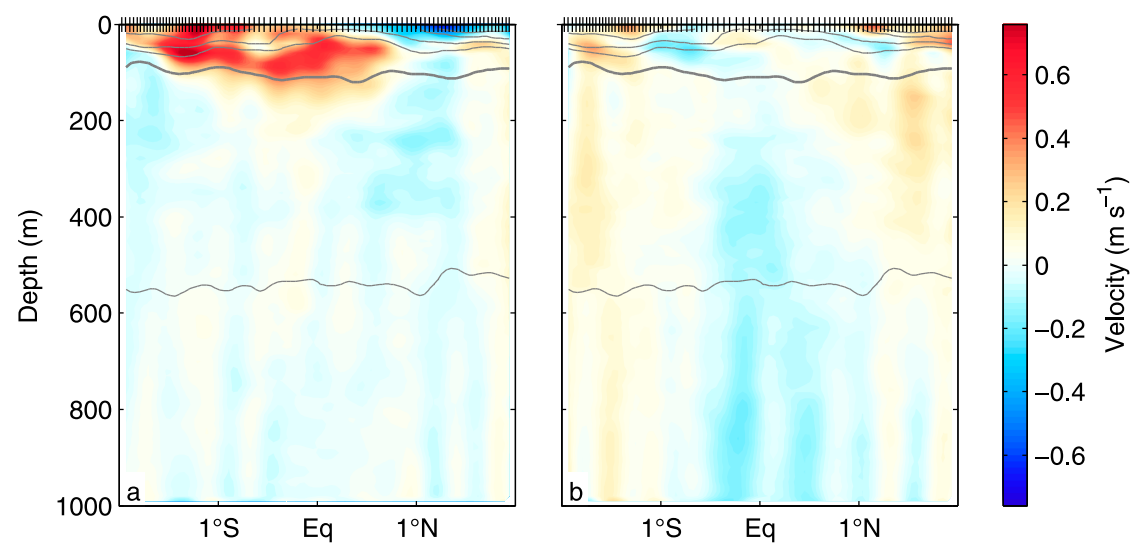

FIG. 19. (a) Eastward and (b) northward velocity estimates across the equator along $93^{\circ} \mathrm{W}$ from mission 152058 following objective mapping using a Gaussian covariance matrix with a 30-km length scale. Gray contours denote isopycnals with a contour interval of $1 \mathrm{~kg} \mathrm{~m}^{-3}$, and the bold line is the $26 \mathrm{~kg} \mathrm{~m}^{-3}$ isopycnal.

relative to the moving glider over a range of $O(10) \mathrm{m}$. Our group has flown ADCPs on Spray gliders since 2005, and missions with externally mounted (e.g., Slocum gliders with Nortek Aquadopp profilers; Miles et al. 2015) and internally mounted [e.g., the Slocum gliders with Teledyne RD Instruments (RDI) Doppler velocity log (DVL)
Explorers used by the Ocean Observatories Initiative] ADCPs on other glider platforms are becoming more common. Here we have shown that glider-based ADCP measurements can improve estimates of vertically averaged velocities, expanded upon the inverse method of recovering absolute velocity profiles using glider-based

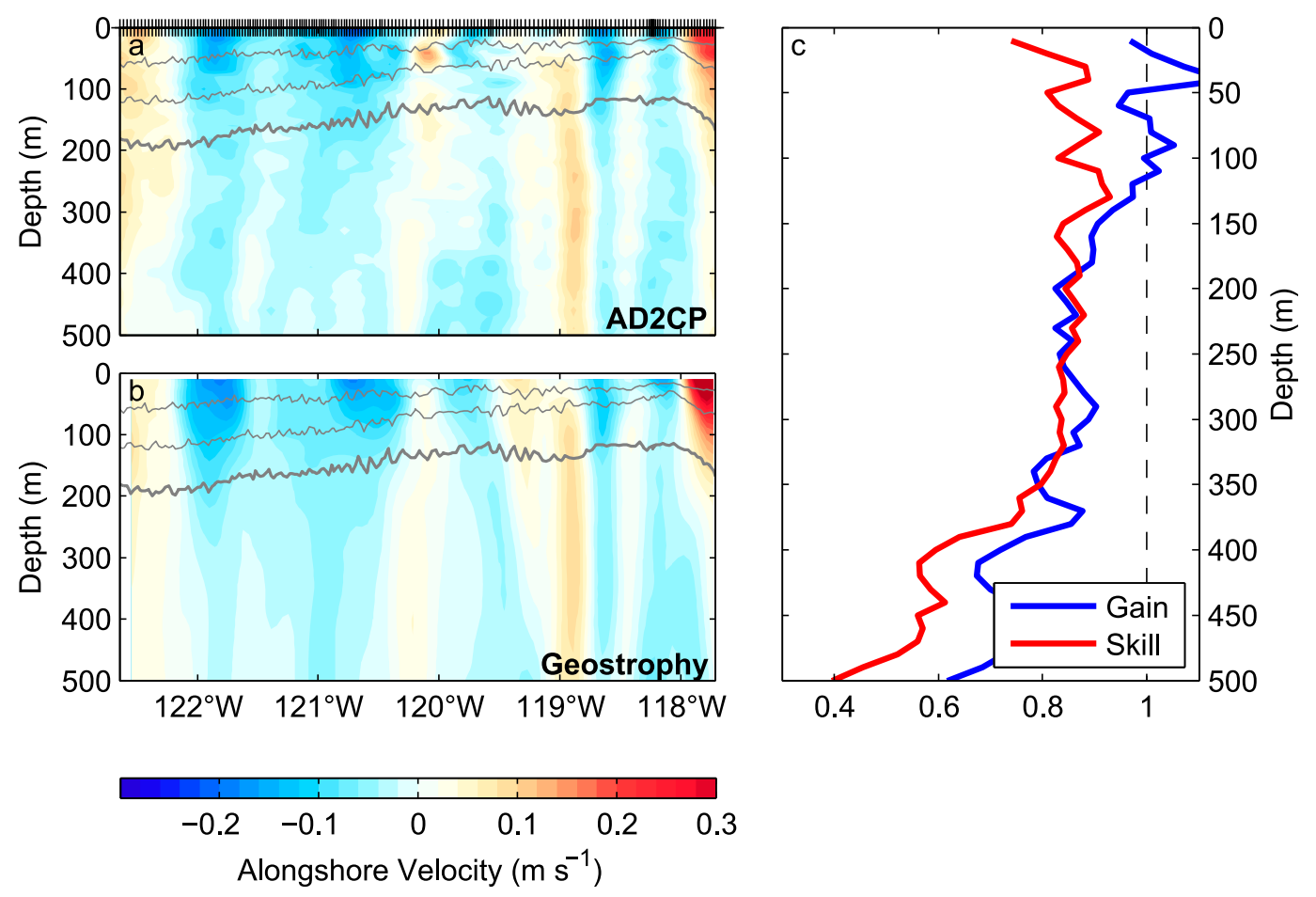

FIG. 20. Comparison of AD2CP-derived and geostrophic estimates of alongshore velocity on CalCOFI Line 90.0 from mission 157030. (a) AD2CP-derived velocities smoothed by objective mapping with a 30-km Gaussian covariance. (b) Absolute geostrophic velocity estimated by objective mapping with the same covariance as in (a). (c) Slope (blue) and skill (red) as a function of depth for the regression of geostrophic velocity on AD2CP-derived velocity. Gray contours in (a),(b) denote isopycnals with a contour interval of $1 \mathrm{~kg} \mathrm{~m}^{-3}$, and the bold line is the $26 \mathrm{~kg} \mathrm{~m}^{-3}$ isopycnal. 


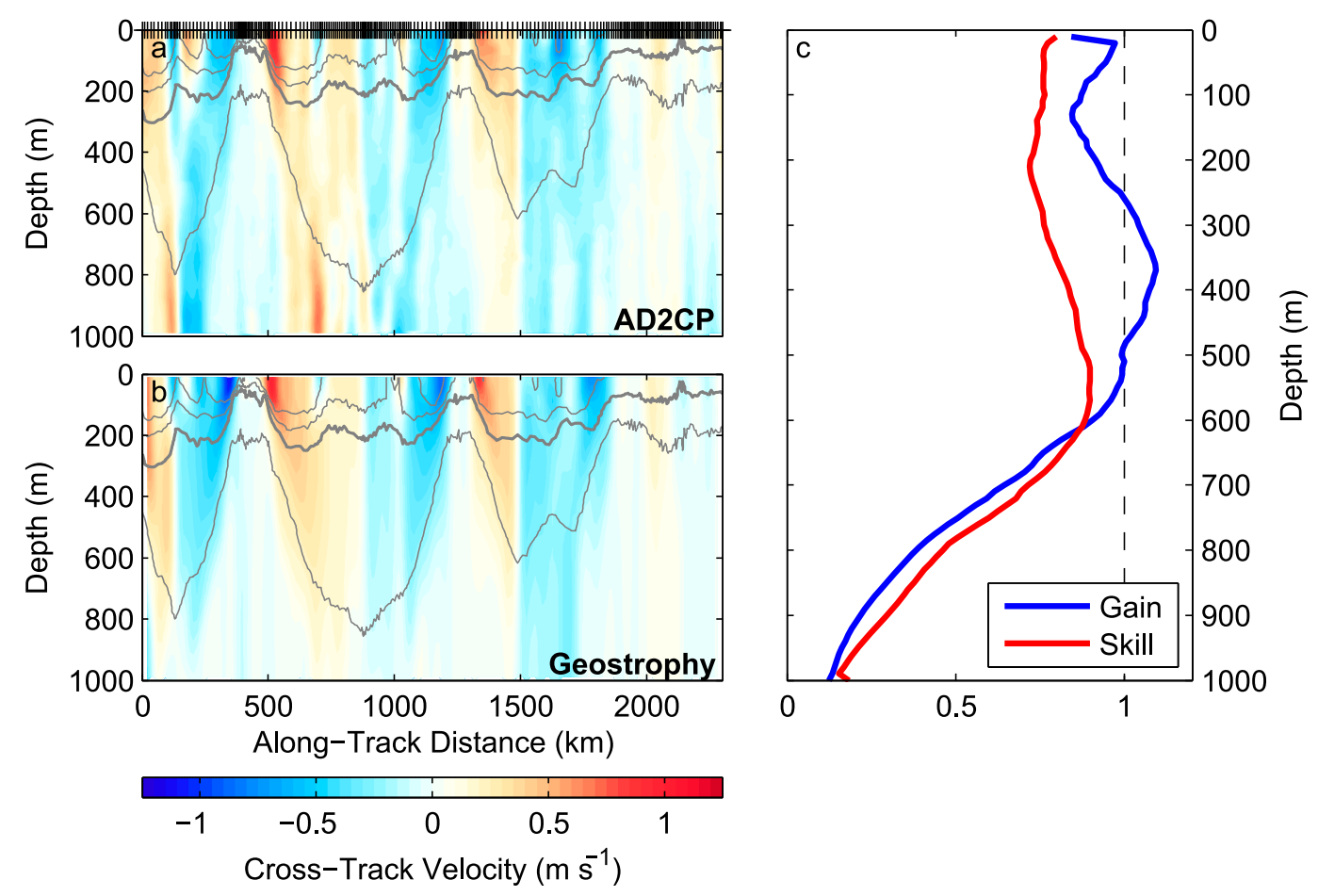

FIG. 21. Comparison of AD2CP-derived and geostrophic estimates of cross-track velocity for a portion of mission 15A065 in the Gulf Stream. (a) AD2CP-derived velocities smoothed by objective mapping with a 50-km Gaussian covariance. (b) Absolute geostrophic velocity estimated by objective mapping with the same covariance as in (a). (c) Slope (blue) and skill (red) as a function of depth for the regression of geostrophic velocity on AD2CP-derived velocity. Gray contours in (a),(b) denote isopycnals with a contour interval of $1 \mathrm{~kg} \mathrm{~m}^{-3}$, and the bold line is the $26 \mathrm{~kg} \mathrm{~m}^{-3}$ isopycnal.

ADCPs, identified and corrected for instrumental bias, and examined the accuracy of resulting absolute velocity profiles. Though our analysis focuses on measurements with Nortek AD2CPs on Spray gliders, the techniques should be applicable to other combinations of ADCPs and gliders.

Relative velocity measurements from the ADCP cells nearest to a glider provide good measurements of the glider's three-dimensional speed through the water (Figs. 6, 7, and 10). A comparison of ADCP measurements with vertical velocity estimated from the time rate of change of depth measured by a glider allows for detection of small misalignments between the ADCP and glider or errors in pitch and roll measurements. Properly oriented ADCP measurements can then be used to estimate dive-dependent angles of attack and sideslip, key parameters in models of glider flight (Fig. 8). These variable angles of attack and sideslip can be used to update estimates of dead-reckoned displacement and vertically averaged currents to account for accumulation of biofouling during glider missions lasting several months (Figs. 9 and 11). Similarly, ADCP measurements could be used to infer effective angles of attack for gliders carrying externally mounted instruments (e.g., Nortek Aquadopp profilers or Rockland Scientific Microriders on Slocum gliders) and subsequently correct vertically averaged velocity estimates to account for the drag of those instruments. Since we run the ADCPs on Spray gliders only during ascent to conserve power, our ADCP measurements cannot replace the use of a model of glider flight to estimate deadreckoned displacement, but in applications where ADCPs can be run throughout a dive cycle, such a use would be possible.

To estimate profiles of absolute horizontal velocity using glider-based ADCPs, we use an inverse technique based on the LADCP processing of Visbeck (2002) and modified for application to gliders by Todd et al. (2011b). Measured profiles of water velocity relative to a glider provide estimates of vertical structure but do not provide information on absolute magnitude. For all missions, vertically averaged current estimates provide key integral constraints on the absolute velocity. We have shown that for locations in which surface velocities are strongly related to the subsurface (largely geostrophic) flow, estimates of surface current speed based on the drift of a glider on the surface provide useful 
additional information for constraining velocity profiles (Figs. 12 and 13) and have modified the inverse technique to use information from these complementary estimates by including user-specified weights on the constraint equations. Though not addressed here, inclusion of bottom-tracking information may also be possible when gliders sample near the seafloor (for details, see Visbeck 2002); like surface drift estimates, we expect that the pointwise constraint obtained from bottom tracking would be insufficient as the sole absolute velocity constraint, particularly since it applies directly to the glider's velocity rather than the water velocity in (5).

We diagnose both an instrumental bias and (presumably) random errors in the glider-based AD2CP measurements. The instrumental bias manifests as anomalous heading-dependent shear in the velocity profiles. By seeking to minimize variance in our estimated velocity profiles (Fig. 18), we are able to correct for this instrumental bias (Table 2; Figs. 14-16). The root cause of the bias remains unknown, and we anticipate working with the manufacturer to identify and remedy the problem. After correcting for shear bias, increasing velocity variance with depth is attributable to increasing errors in the AD2CP measurements due to compromised performance at depth, presumably due to a lack of acoustic scatterers (e.g., Fig. 1). Root-mean-square errors resulting from this compromised performance range from 0.08 to $0.24 \mathrm{~m} \mathrm{~s}^{-1}$ for individual profiles in different regions; these relatively large errors suggest a need to combine multiple profiles in order to reduce random errors.

As underwater gliders continue to see increased use in oceanography, we expect that use of glider-based ADCPs will become more common as well. Through more than a decade of operational usage of ADCPs on Spray gliders in many oceanographic settings, three of which are shown herein, our group has demonstrated the utility of velocity profiling with glider-based ADCPs. We anticipate that the techniques described here and in the preceding work will see widespread use with a variety of platform and instrument combinations.

Acknowledgments. We thank Atle Lohrmann, Sven Nylund, and others at Nortek for working with us to integrate the AD2CP on Spray and for their ongoing efforts to improve the instrument. Spray glider missions were supported by the National Science Foundation (OCE-1232971, OCE-1233282), the National Oceanic and Atmospheric Administration (NA10OAR4320156, NA15OAR4320071), Eastman Chemical Company, the Oceans and Climate Change Institute at WHOI, and the W. Van Alan Clark Jr. Chair for Excellence in Ocean- ography at WHOI. RET acknowledges additional support for analysis and publication from the National Science Foundation (OCE-1633911). Data used herein are available by request from the authors.

\section{REFERENCES}

Davis, R. E., 2010: On the coastal-upwelling overturning cell. J. Mar. Res., 68, 369-385, doi:10.1357/002224010794657173.

, C. C. Eriksen, and C. P. Jones, 2003: Autonomous bouyancydriven underwater gliders. Technology and Applications of Autonomous Underwater Vehicles, G. Griffiths, Ed., Taylor and Francis, 37-58.

—, M. D. Ohman, D. L. Rudnick, J. T. Sherman, and B. A. Hodges, 2008: Glider surveillance of physics and biology in the southern California Current System. Limnol. Oceanogr., 53, 2151-2168, doi:10.4319/lo.2008.53.5_part_2.2151.

, W. S. Kessler, and J. T. Sherman, 2012: Gliders measure western boundary current transport from the South Pacific to the equator. J. Phys. Oceanogr., 42, 2001-2013, doi:10.1175/ JPO-D-12-022.1.

Eriksen, C. C., T. J. Osse, R. D. Light, T. Wen, T. W. Lehman, P. L. Sabin, J. W. Ballard, and A. M. Chiodi, 2001: Seaglider: A long-range autonomous underwater vehicle for oceanographic research. IEEE J. Oceanic Eng., 26, 424-436, doi:10.1109/ 48.972073.

Fischer, J., and M. Visbeck, 1993: Deep velocity profiling with selfcontained ADCPs. J. Atmos. Oceanic Technol., 10, 764-773, doi:10.1175/1520-0426(1993)010<0764:DVPWSC > 2.0.CO;2.

Fofonoff, N. P., and R. C. Millard Jr., 1983: Algorithms for computation of fundamental properties of seawater. UNESCO Technical Papers in Marine Science 44, 53 pp.

Halkin, D. T., and H. T. Rossby, 1985: The structure and transport of the Gulf Stream at $73^{\circ}$ W. J. Phys. Oceanogr., 15, 1439-1452, doi:10.1175/1520-0485(1985)015<1439:TSATOT>2.0.CO;2.

Johns, W. E., T. J. Shay, J. M. Bane, and D. R. Watts, 1995: Gulf Stream structure, transport, and recirculation near $68^{\circ} \mathrm{W}$. J. Geophys. Res., 100, 817-838, doi:10.1029/94JC02497.

Johnston, T. M. S., and D. L. Rudnick, 2015: Trapped diurnal internal tides, propagating semidiurnal internal tides, and mixing estimates in the California Current System from sustained glider observations, 2006-2012. Deep-Sea Res. II, 112, 61-78, doi:10.1016/j.dsr2.2014.03.009.

Miles, T., G. Seroka, J. Kohut, O. Schofield, and S. Glenn, 2015: Glider observations and modeling of sediment transport in Hurricane Sandy. J. Geophys. Res. Oceans, 120, 1771-1791, doi:10.1002/2014JC010474.

Ohman, M. D., and Coauthors, 2013: Autonomous ocean measurements in the California Current ecosystem. Oceanography, 26, 18-25, doi:10.5670/oceanog.2013.41.

Rossby, T., and H.-M. Zhang, 2001: The near-surface velocity and potential vorticity structure of the Gulf Stream. J. Mar. Res., 59, 949-975, doi:10.1357/00222400160497724.

Rudnick, D. L., 2016: Ocean research enabled by underwater gliders. Annu. Rev. Mar. Sci., 8, 519-541, doi:10.1146/ annurev-marine-122414-033913.

— water gliders. J. Geophys. Res., 116, C08010, doi:10.1029/ 2010JC006849.

, R. E. Davis, C. C. Eriksen, D. M. Fratantoni, and M. J. Perry, 2004: Underwater gliders for ocean research. Mar. Technol. Soc. J., 38, 73-84, doi:10.4031/002533204787522703. 
- T. M. S. Johnston, and J. T. Sherman, 2013: High-frequency internal waves near the Luzon Strait observed by underwater gliders. J. Geophys. Res. Oceans, 118, 774-784, doi:10.1002/ jgrc.20083.

_ R. E. Davis, and J. T. Sherman, 2016: Spray underwater glider operations. J. Atmos. Oceanic Technol., 33, 1113-1122, doi:10.1175/JTECH-D-15-0252.1.

Schofield, O., and Coauthors, 2007: Slocum gliders: Robust and ready. J. Field Rob., 24, 473-485, doi:10.1002/rob.20200.

Sherman, J., R. E. Davis, W. B. Owens, and J. Valdes, 2001: The autonomous underwater glider "Spray." IEEE J. Oceanic Eng., 26, 437-446, doi:10.1109/48.972076.

Todd, R. E., D. L. Rudnick, and R. E. Davis, 2009: Monitoring the greater San Pedro Bay region using autonomous underwater gliders during fall of 2006. J. Geophys. Res., 114, C06001, doi:10.1029/2008JC005086.

, and M. D. Ohman, 2011a: Underwater gliders reveal rapid arrival of El Niño effects off California's coast. Geophys. Res. Lett., 38, L03609, doi:10.1029/ 2010GL046376.
M. R. Mazloff, R. E. Davis, and B. D. Cornuelle, 2011b: Poleward flows in the southern California Current System: Glider observations and numerical simulation. J. Geophys. Res., 116, C02026, doi:10.1029/2010JC006536.

, — - — B. D. Cornuelle, and R. E. Davis, 2012: Thermohaline structure in the California Current System: Observations and modeling of spice variance. J. Geophys. Res., 117, C02008, doi:10.1029/2011JC007589.

— W. B. Owens, and D. L. Rudnick, 2016: Potential vorticity structure in the North Atlantic western boundary current from underwater glider observations. J. Phys. Oceanogr., 46, $327-$ 348, doi:10.1175/JPO-D-15-0112.1.

Visbeck, M., 2002: Deep velocity profiling using lowered acoustic Doppler current profilers: Bottom track and inverse solutions. J. Atmos. Oceanic Technol., 19, 794-807, doi:10.1175/ 1520-0426(2002)019<0794:DVPULA > 2.0.CO;2.

Zaba, K. D., and D. L. Rudnick, 2016: The 2014-2015 warming anomaly in the Southern California Current System observed by underwater gliders. Geophys. Res. Lett., 43, 1241-1248, doi:10.1002/2015GL067550. 